\title{
Synthesis of 2'-C- $\beta$-difluoromethylribonucleosides
}

\section{and enzymatic incorporation into oligonucleotides}

Jing-Dong Ye, Xiangmin Liao ${ }^{\dagger}$ and Joseph A. Piccirilli*

Howard Hughes Medical Institute, Department of Biochemistry \& Molecular Biology, and Department of Chemistry, the University of Chicago, 5841 S. Maryland Ave. MC 1028, Chicago, Illinois 60637

${ }^{\dagger}$ Present address: GlaxoSmithKline, UP 1110, 1250 S. Collegeville Road, Collegeville, PA 19426

\section{Supporting Information}

Table of Contents

1. ${ }^{1} \mathrm{H}$ NMR of 3

2. ${ }^{13} \mathrm{C}$ NMR of 3

3. ${ }^{19} \mathrm{~F}-{ }^{1} \mathrm{H}$ NOE of 3

4. ${ }^{1} \mathrm{H}$ NMR of 4 S6

5. ${ }^{13} \mathrm{C}$ NMR of 4

S7

6. ${ }^{1} \mathrm{H}$ NMR of 6 S8

7. ${ }^{13} \mathrm{C}$ NMR of 6 S9

8. ${ }^{19} \mathrm{~F}-{ }^{1} \mathrm{H}$ NOE of 6 $\mathrm{S} 10$

9. NOESY of 6

10. ${ }^{1} \mathrm{H}$ NMR of 7

11. ${ }^{13} \mathrm{C}$ NMR of 7

12. ${ }^{1} \mathrm{H}$ NMR of 8

13. NOESY of 8

14. ${ }^{1} \mathrm{H}$ NMR of $9 \mathbf{a}$

S16

15. ${ }^{13} \mathrm{C}$ NMR of $9 \mathbf{a}$ 
17. ${ }^{1} \mathrm{H}$ NMR of $\mathbf{9 b}$

18. ${ }^{13} \mathrm{C}$ NMR of $9 b$

19. NOESY of $\mathbf{9 b}$

20. ${ }^{1} \mathrm{H}$ NMR of $9 c$

21. ${ }^{1} \mathrm{H}$ NMR of $\mathbf{1 0 a}$

22. ${ }^{13} \mathrm{C}$ NMR of $\mathbf{1 0 a}$

23. ${ }^{1} \mathrm{H}$ NMR of $\mathbf{1 0 b}$ S25

24. ${ }^{1} \mathrm{H}$ NMR of $\mathbf{1 0 c}$ S26

$25 .{ }^{1} \mathrm{H}$ NMR of $\mathbf{1 5}$

26. ${ }^{13} \mathrm{C}$ NMR of $\mathbf{1 5}$ S28

27. ${ }^{1} \mathrm{H}$ NMR of $\mathbf{1 6}$ S29

28. ${ }^{1} \mathrm{H}$ NMR of 17

29. ${ }^{1} \mathrm{H}$ NMR of $\mathbf{1 8}$

$30 .{ }^{13} \mathrm{C}$ NMR of $\mathbf{1 8}$

31. ${ }^{1} \mathrm{H}$ NMR of $\mathbf{1 9 a}$

32. ${ }^{13} \mathrm{C}$ NMR of $\mathbf{1 9 a}$

35. ${ }^{1} \mathrm{H}$ NMR of $\mathbf{2 0 a}$

36. ${ }^{13} \mathrm{C}$ NMR of $\mathbf{2 0 a}$

37. ${ }^{1} \mathrm{H}$ NMR of $\mathbf{2 0 b}$

38. ${ }^{1} \mathrm{H}$ NMR of 21 

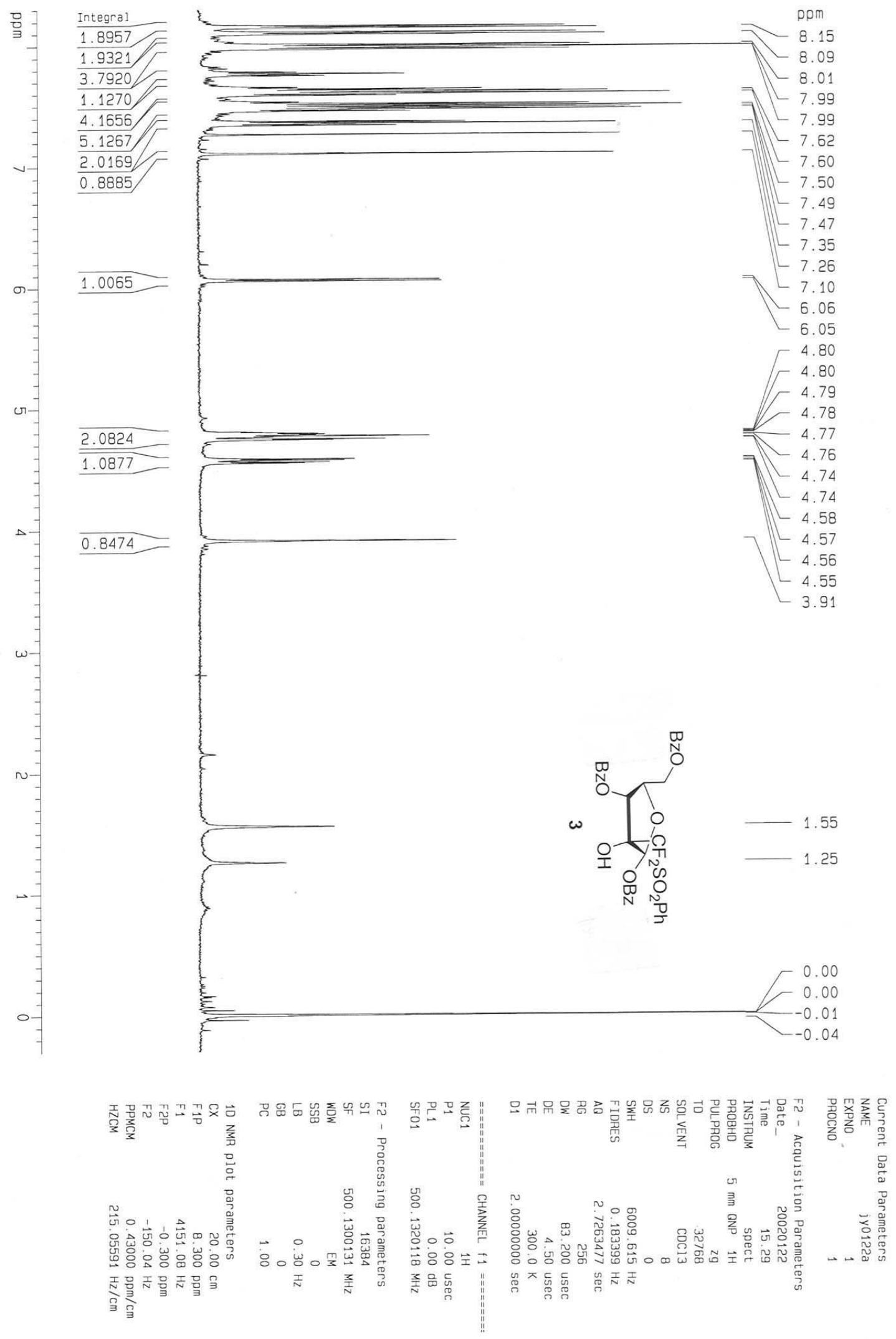

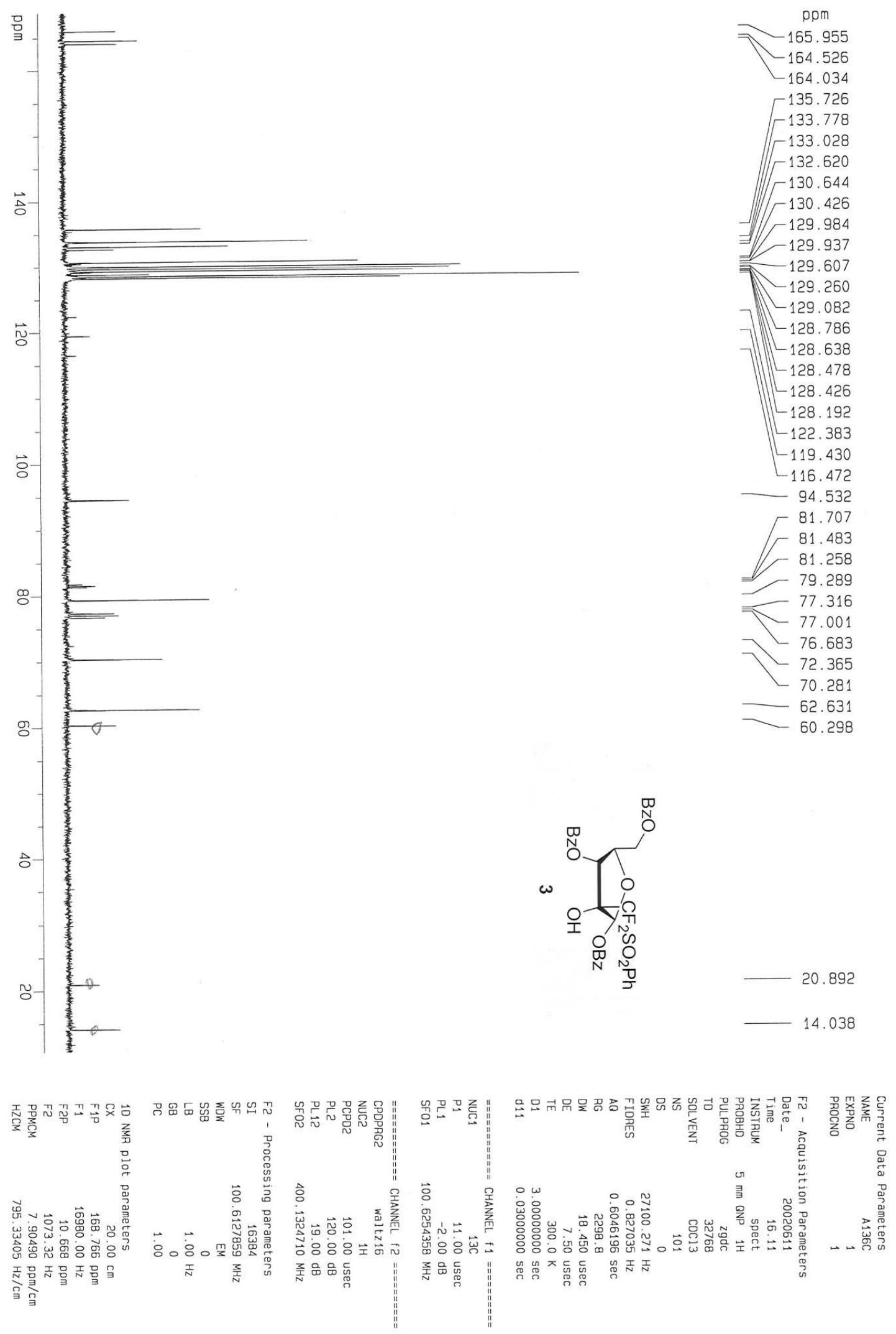

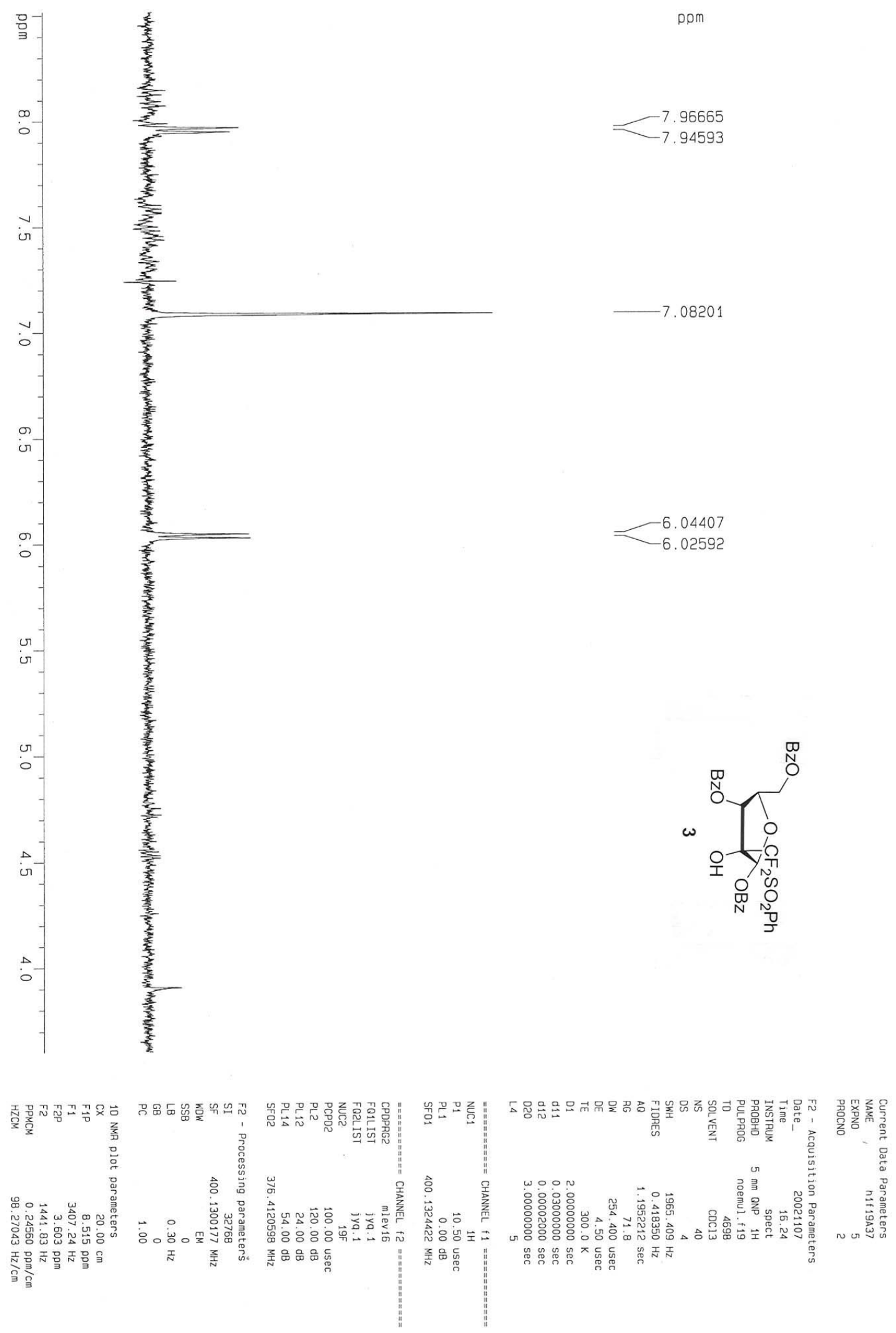

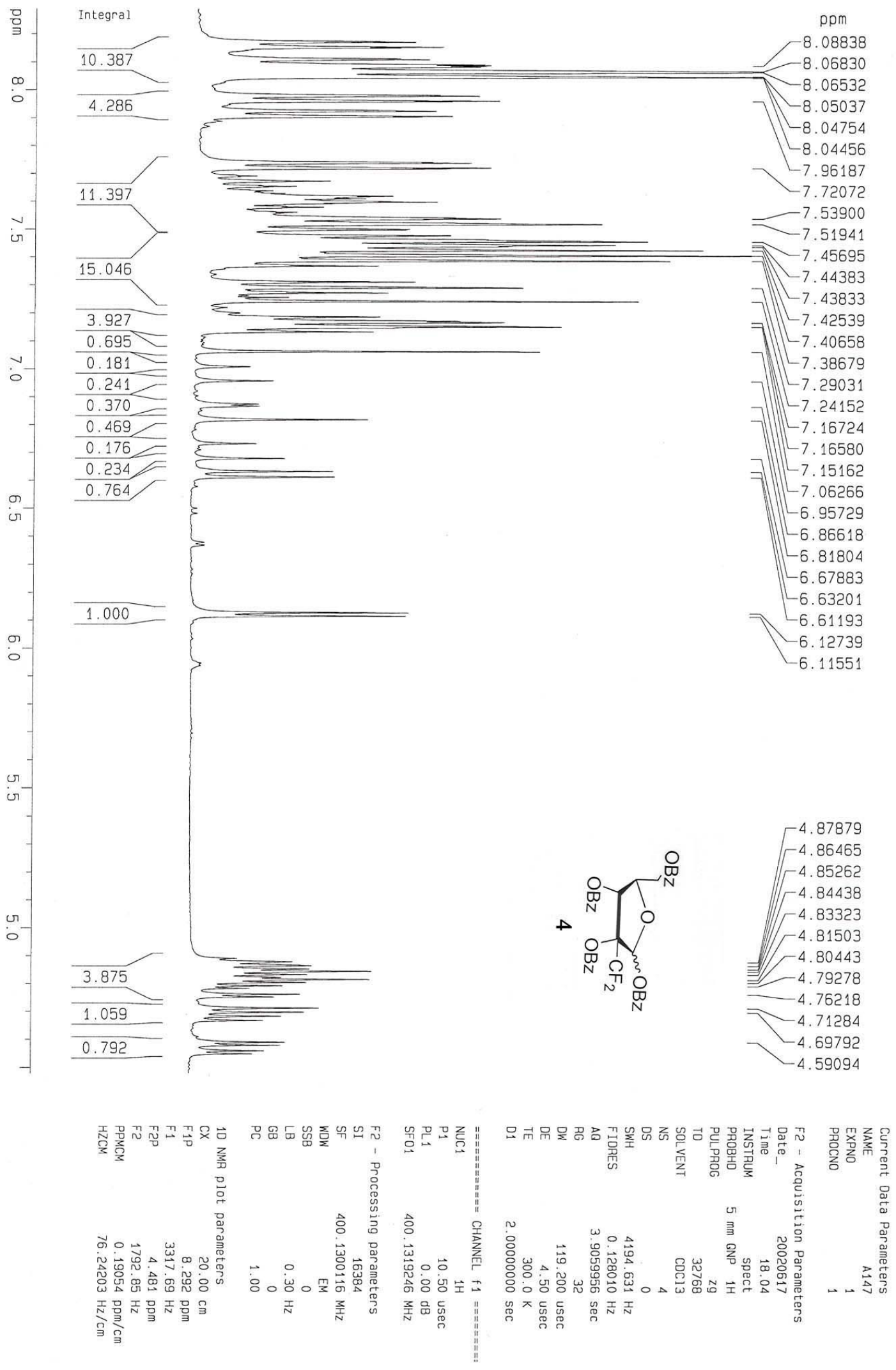

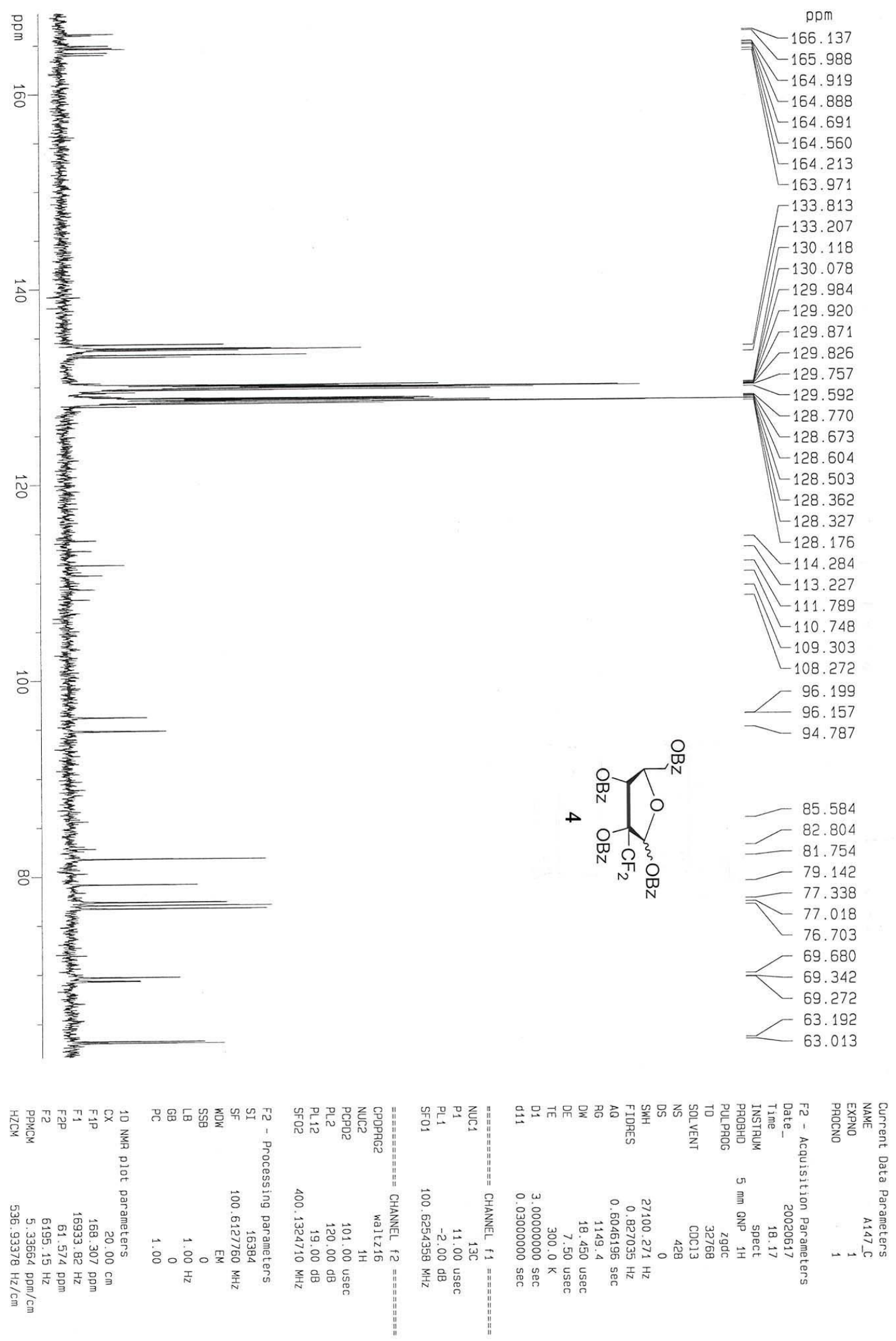

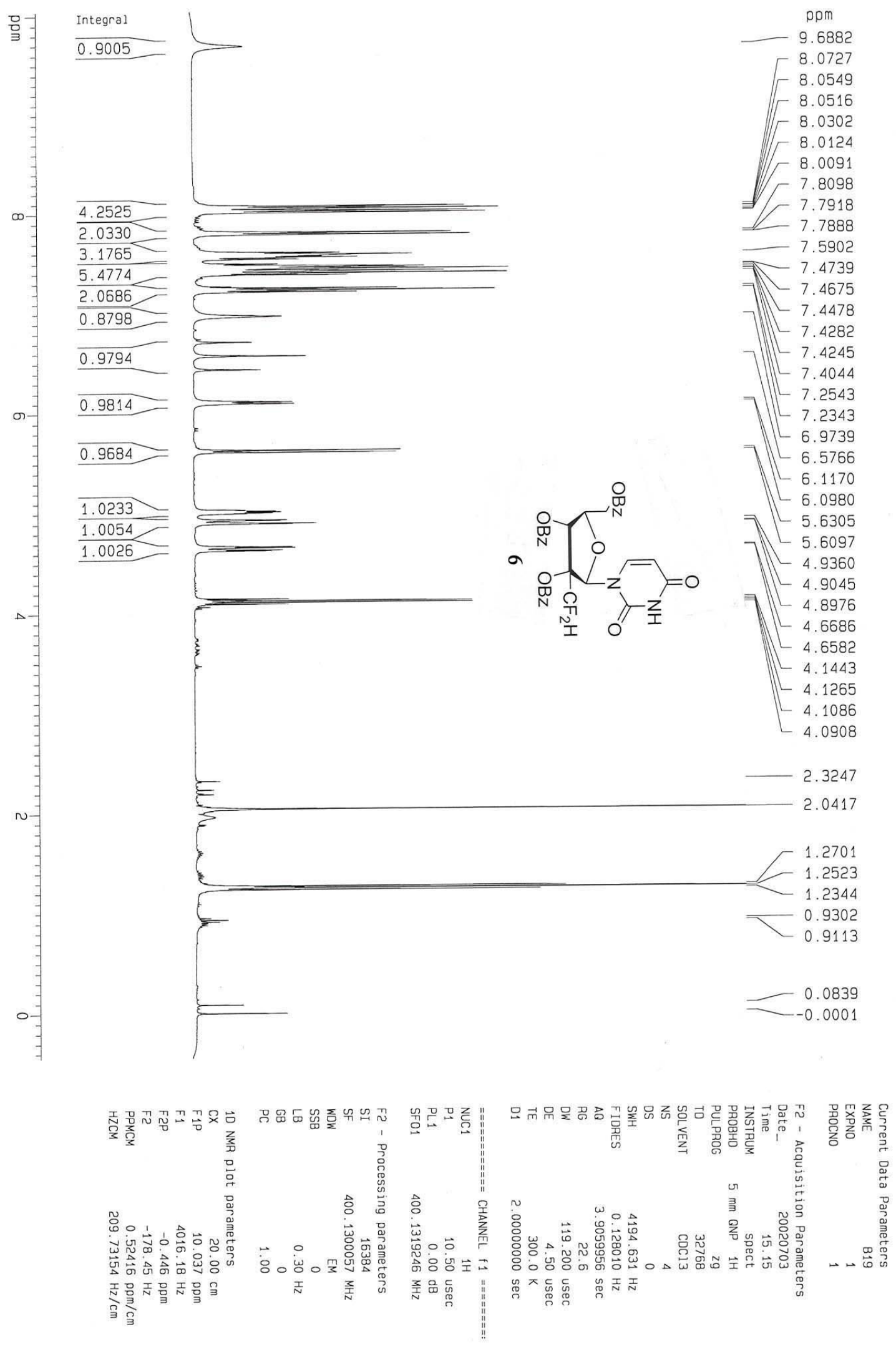

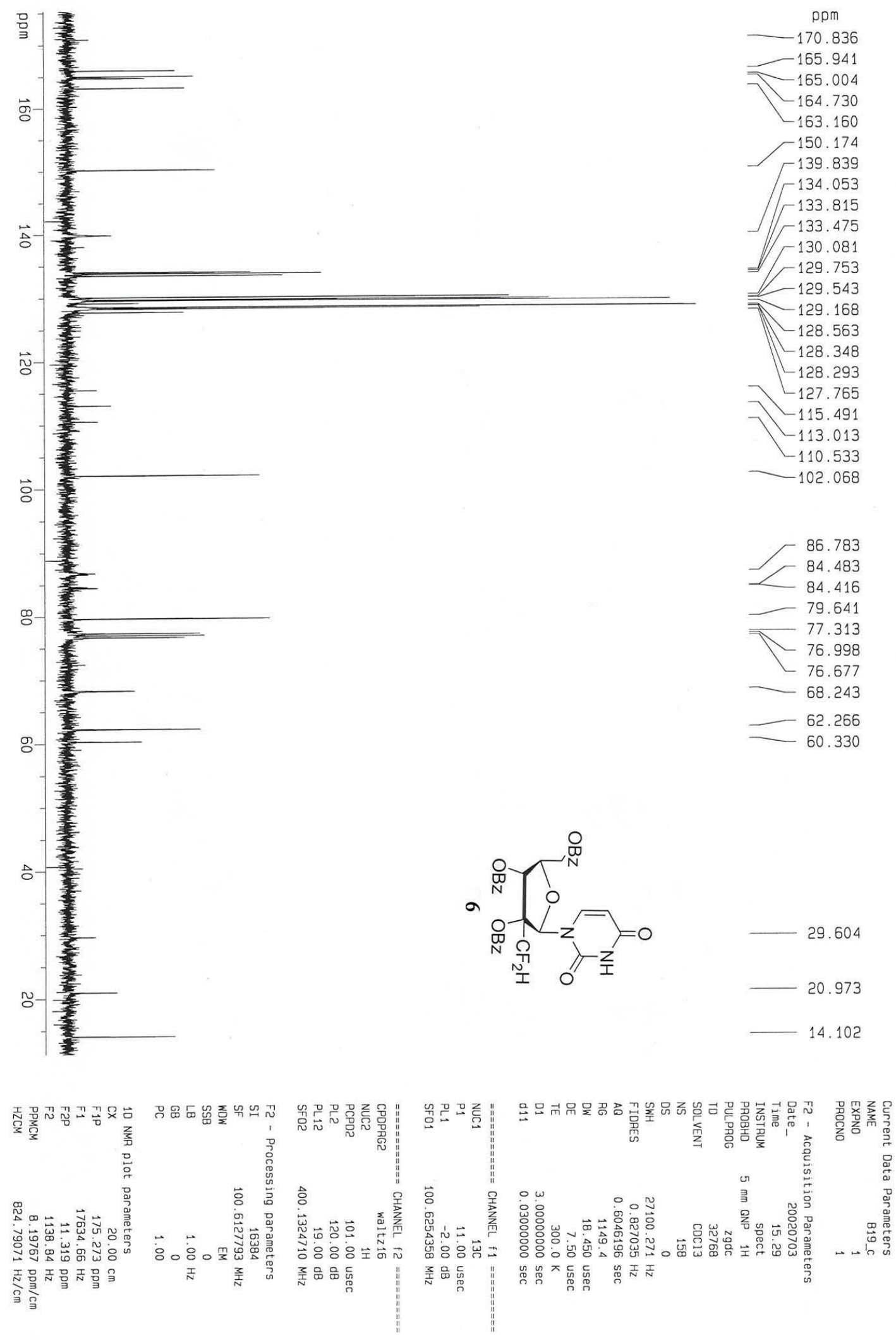


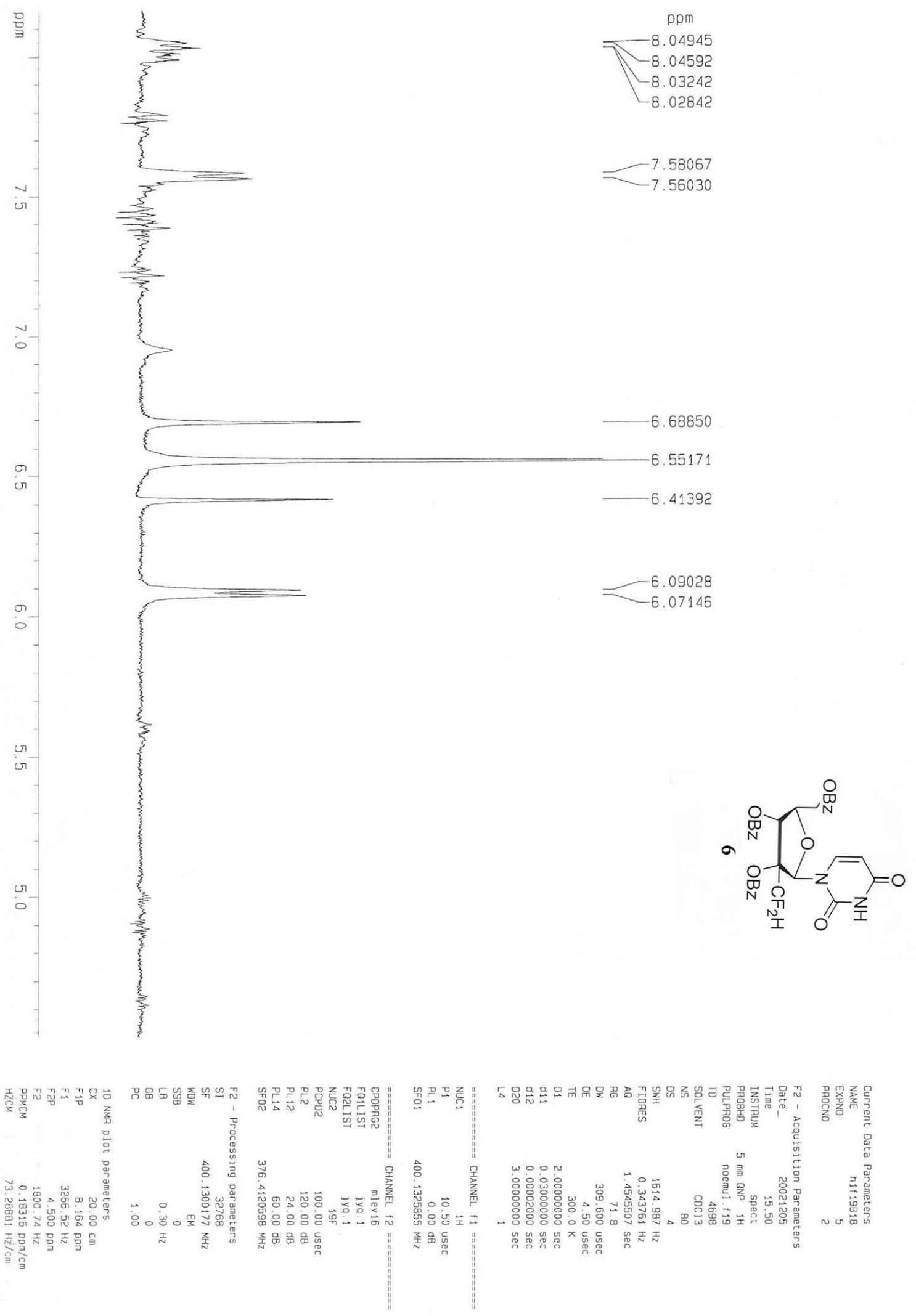




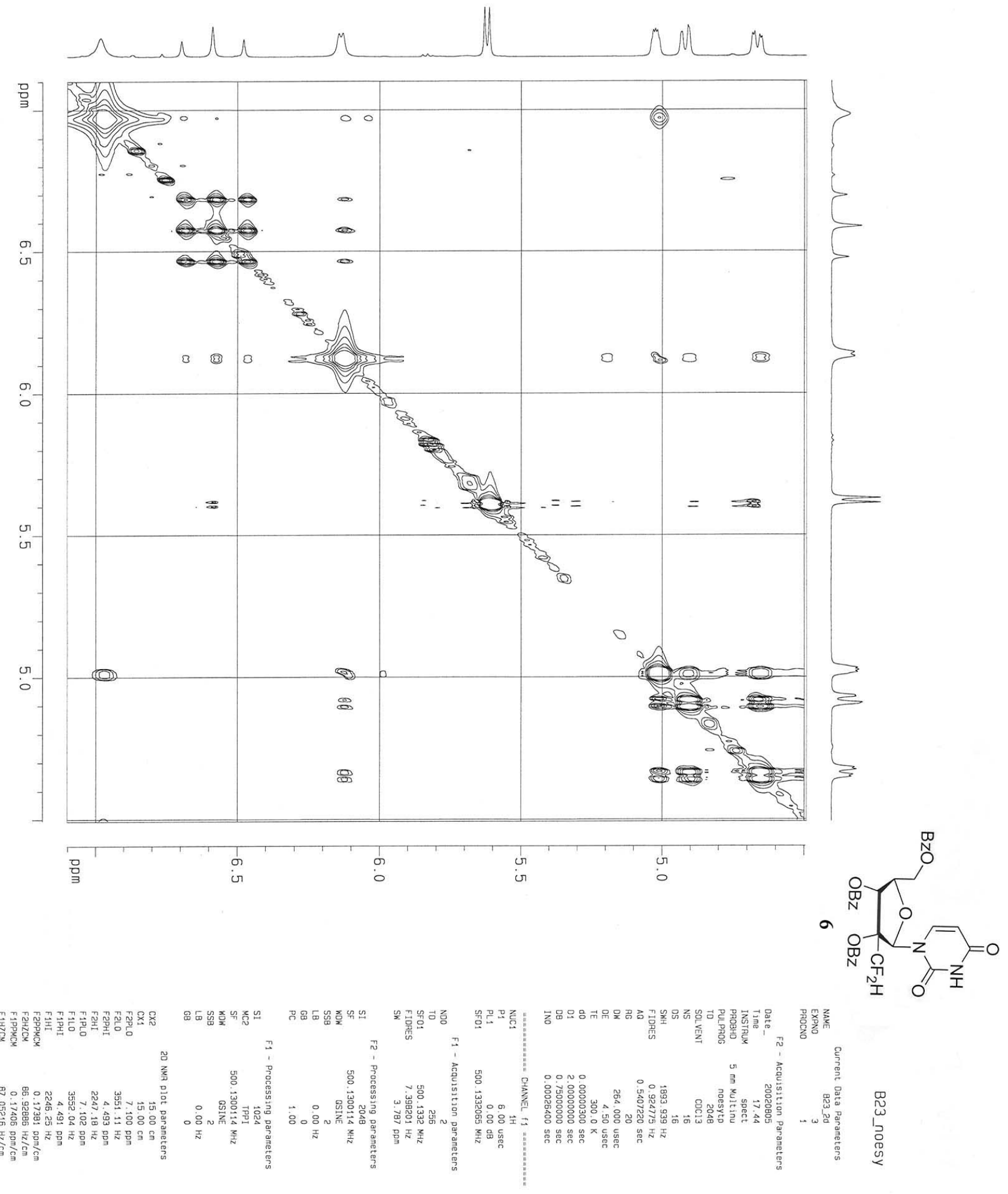



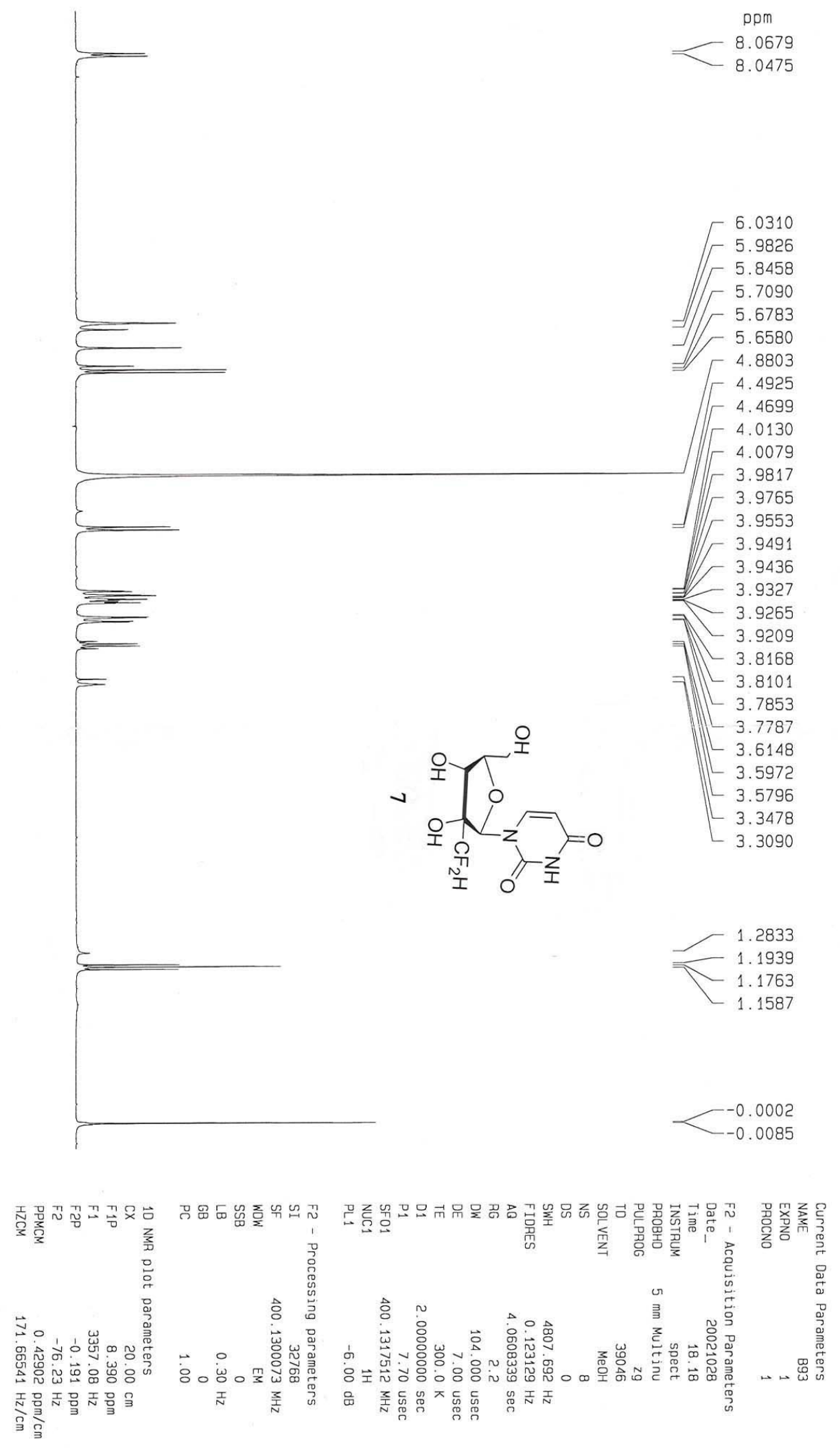

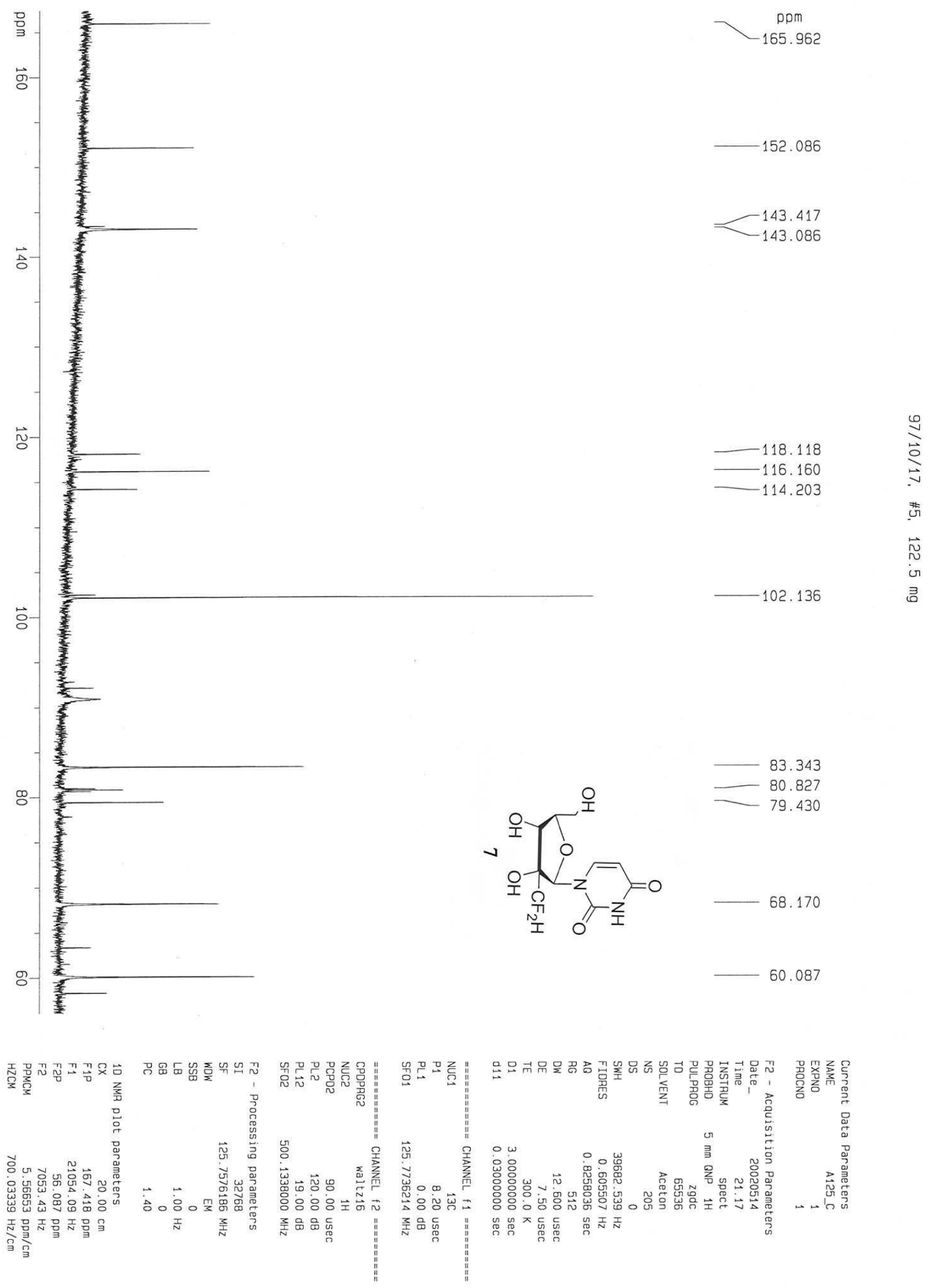

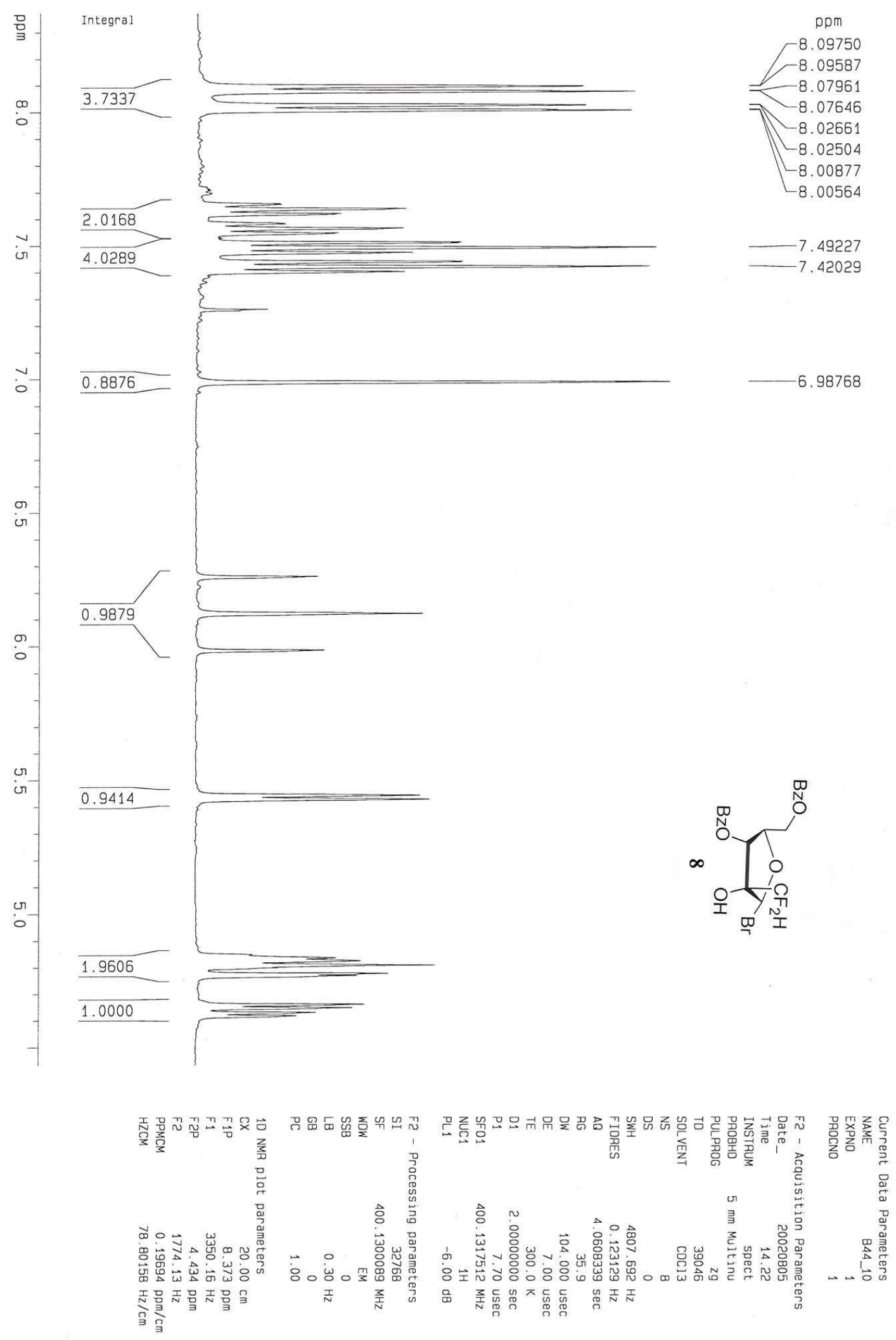


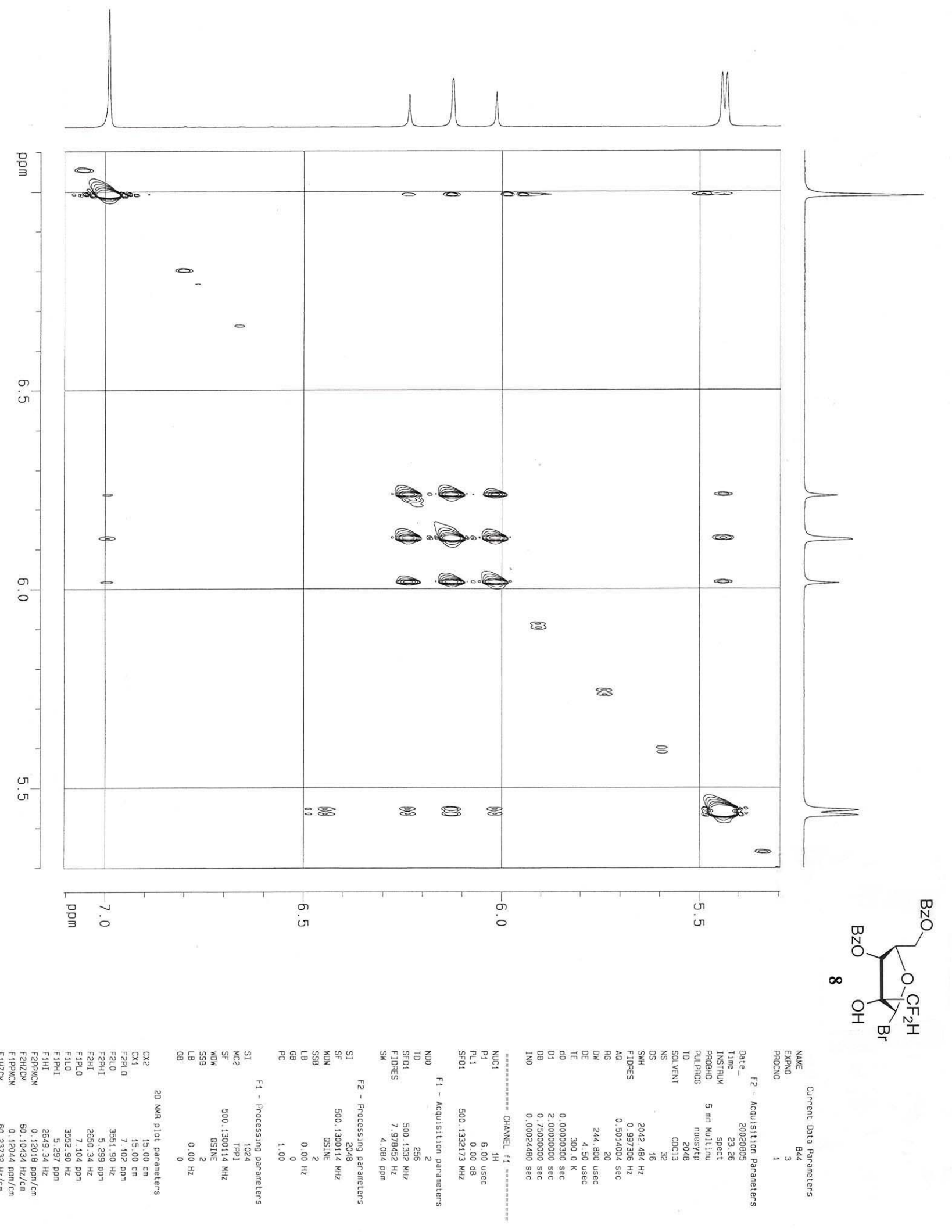



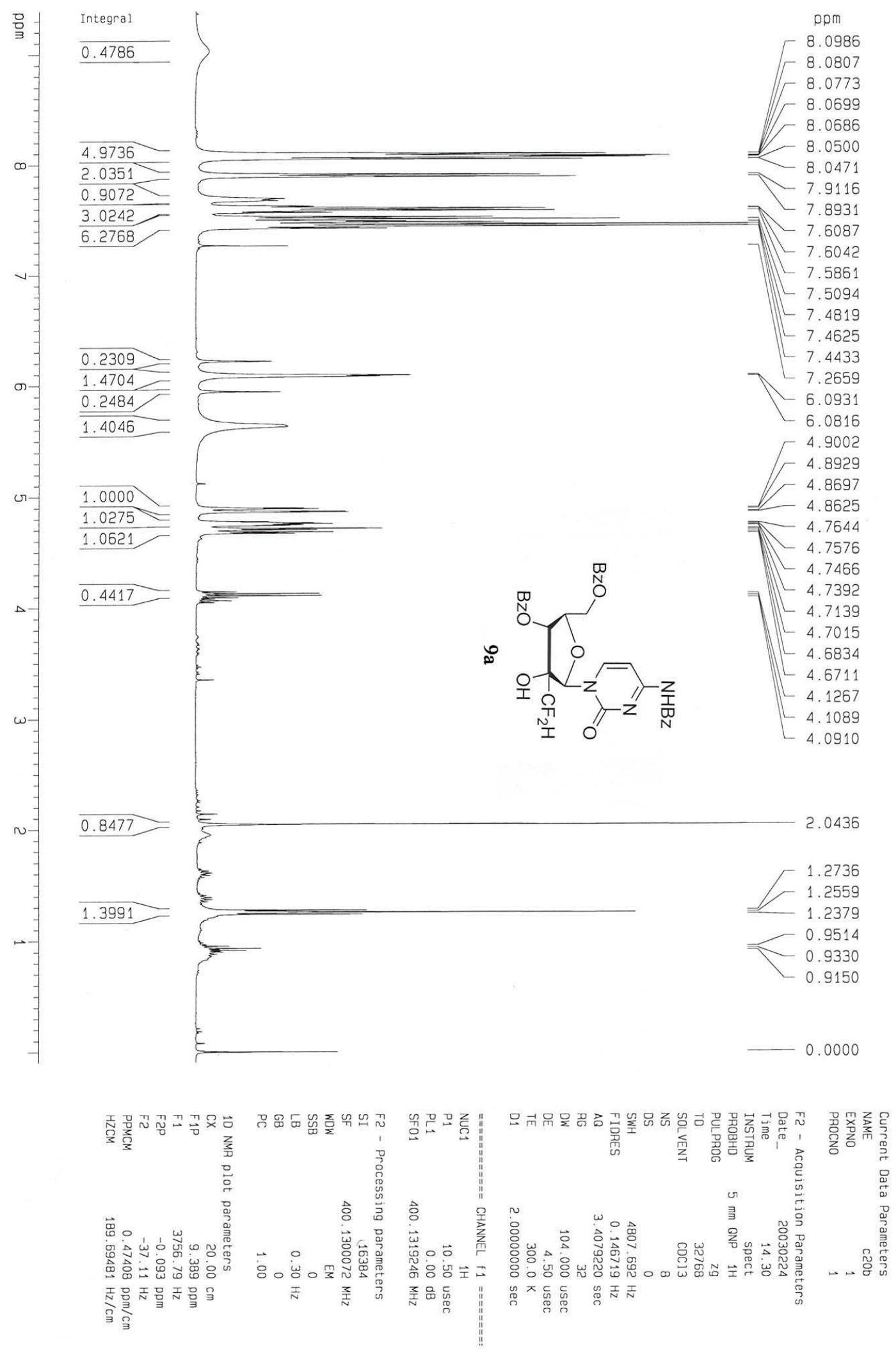


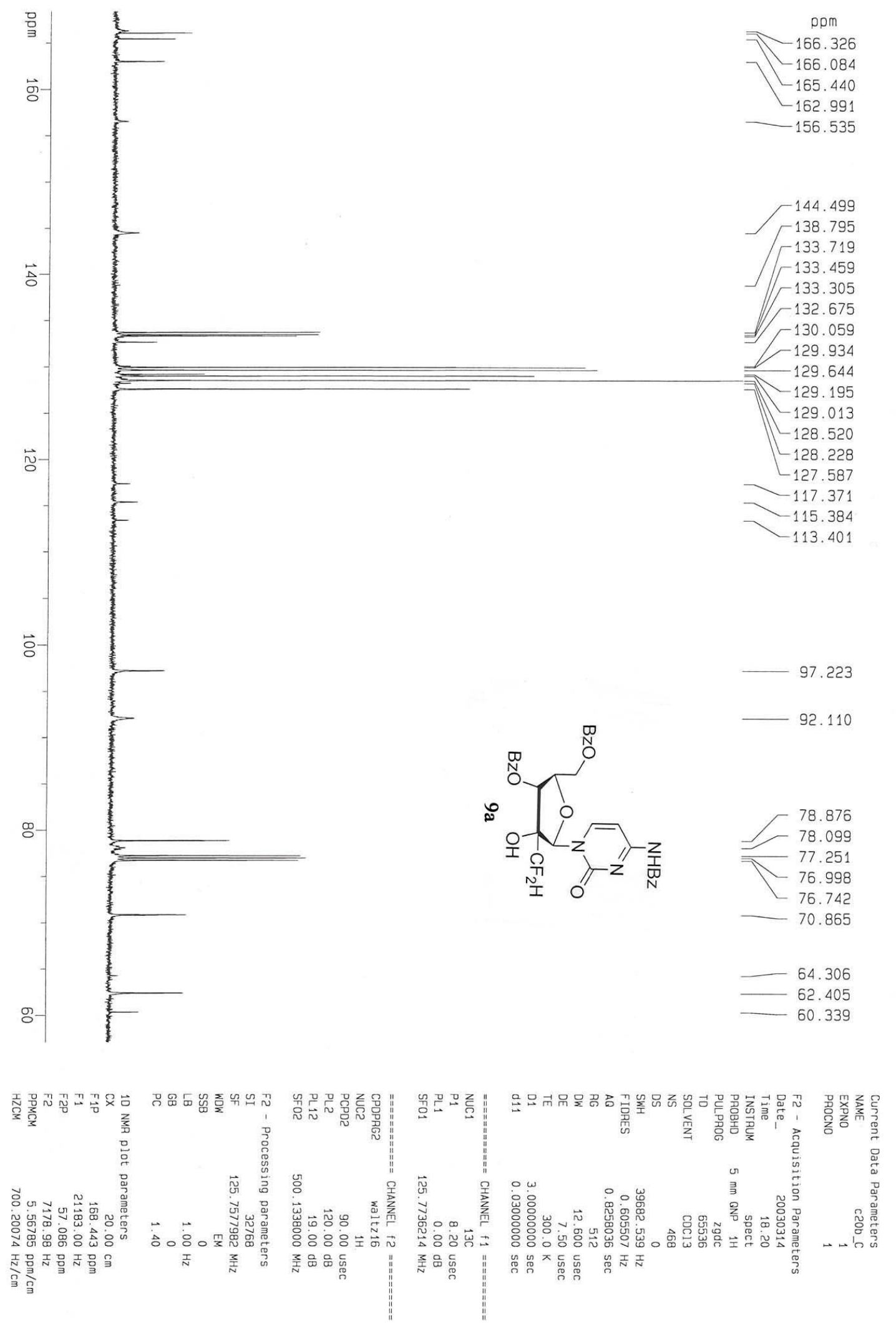




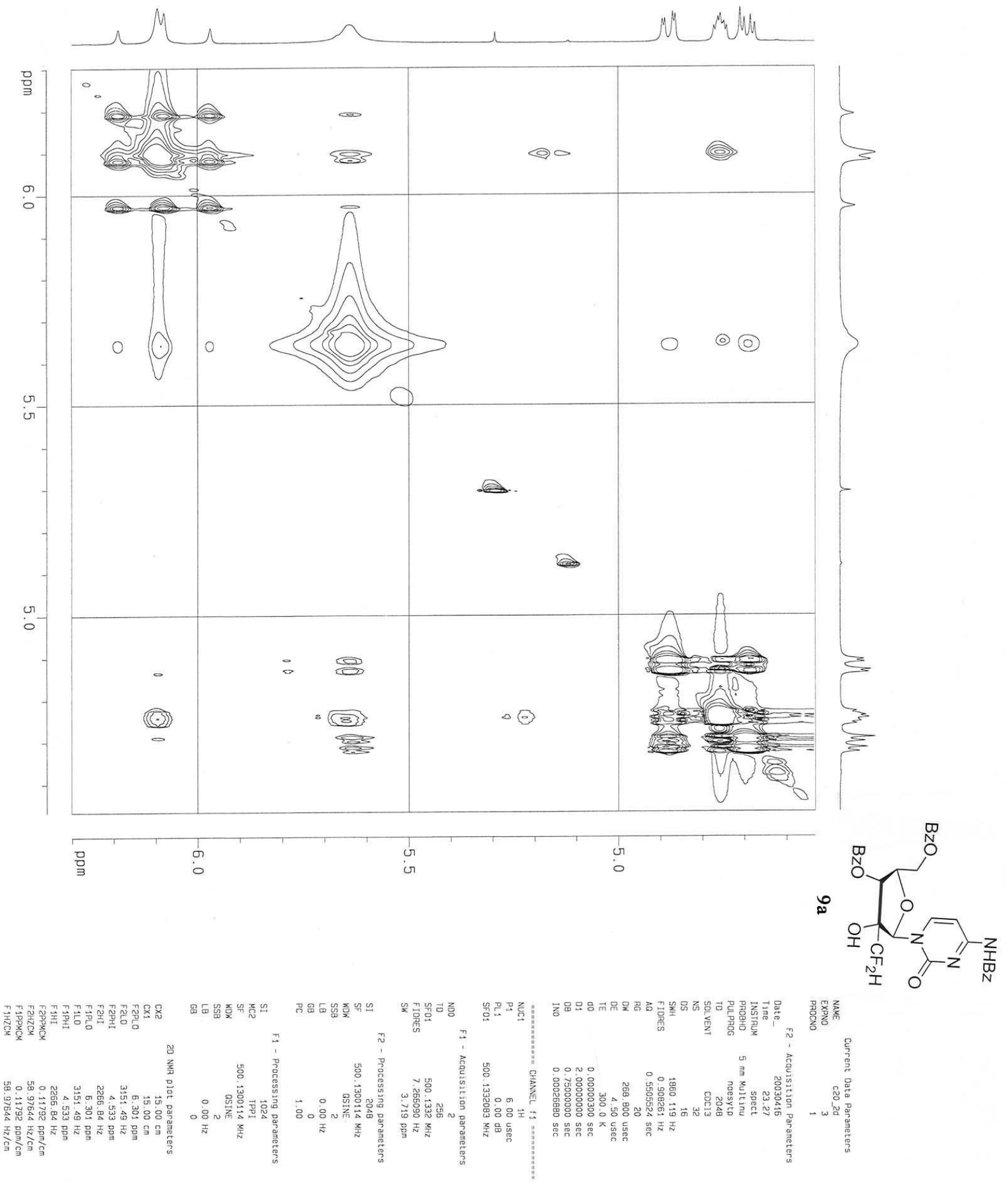



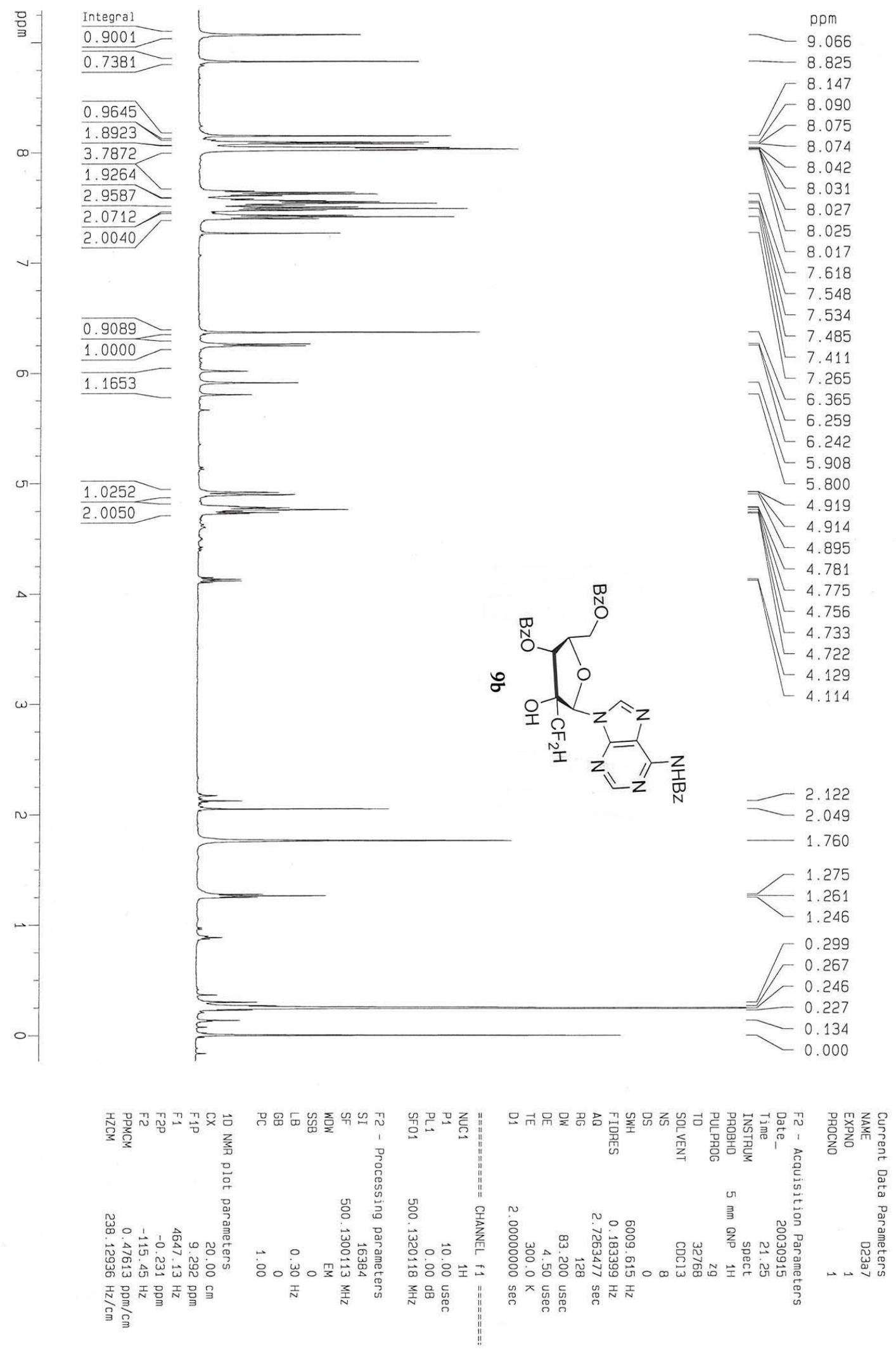

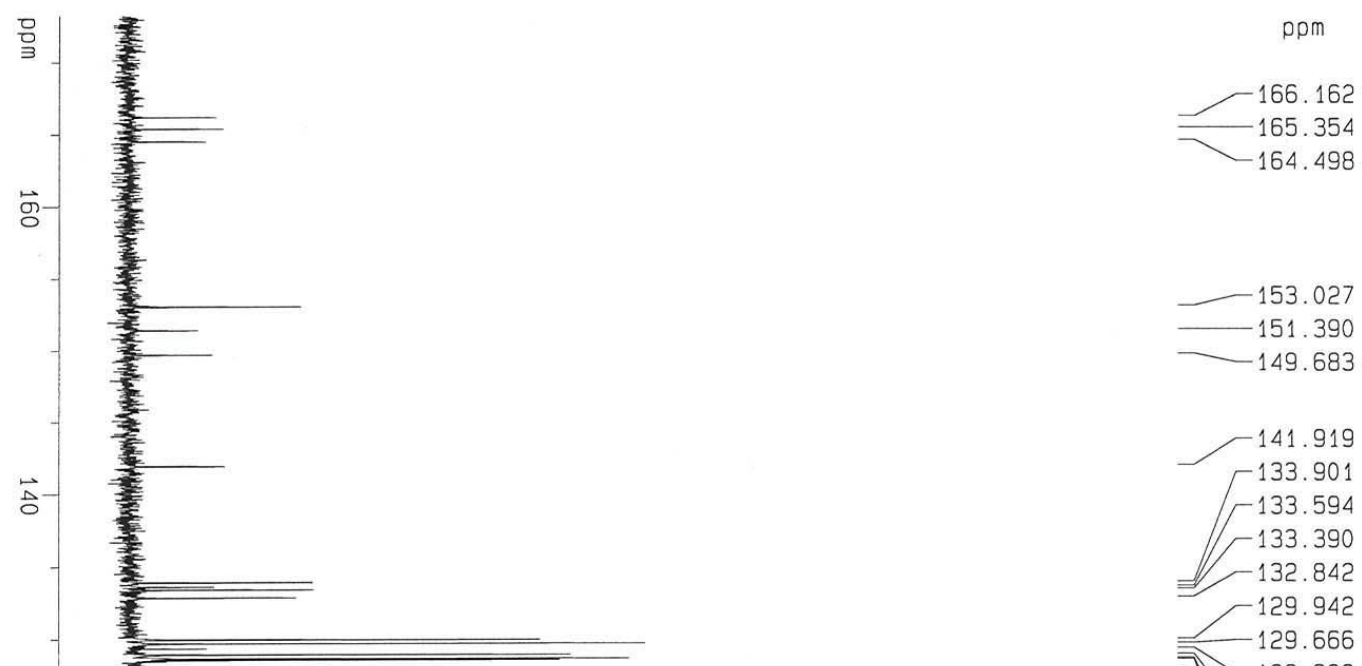

129.942
-129.666

$-129.329$

$-128.904$

$-128.635$

$-128.536$

$-127.828$

$-122.963$

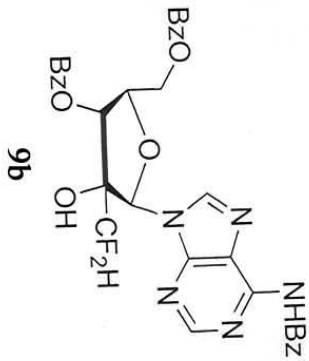

$-113.741$

90.807

ळ

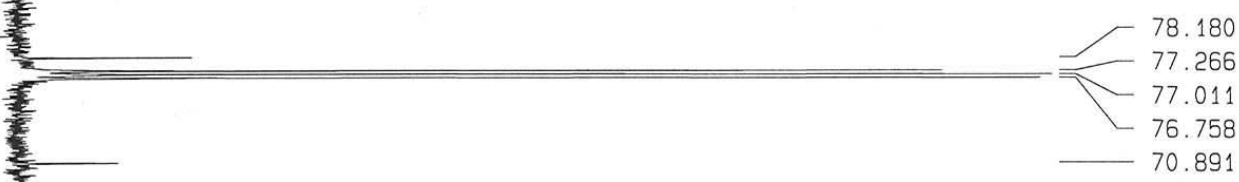

62.936

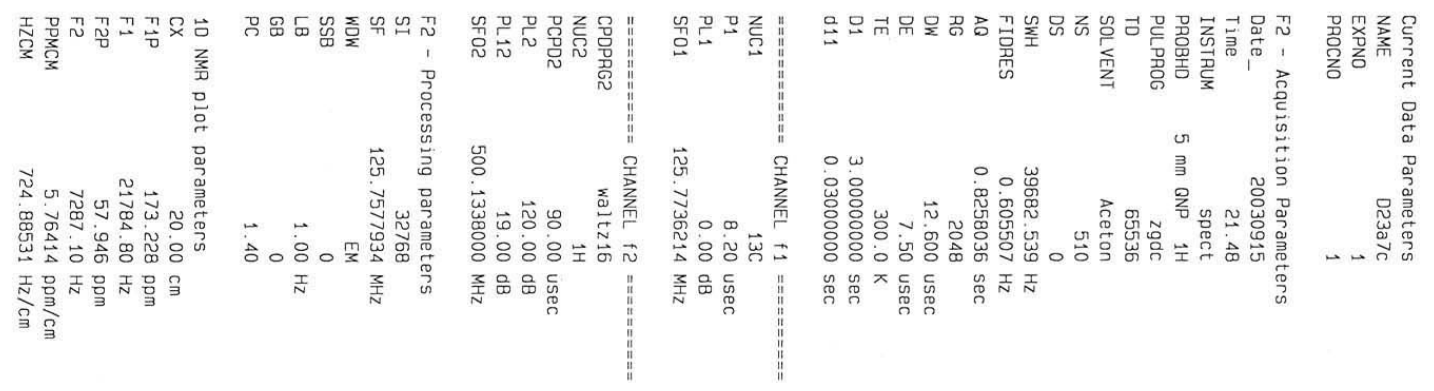




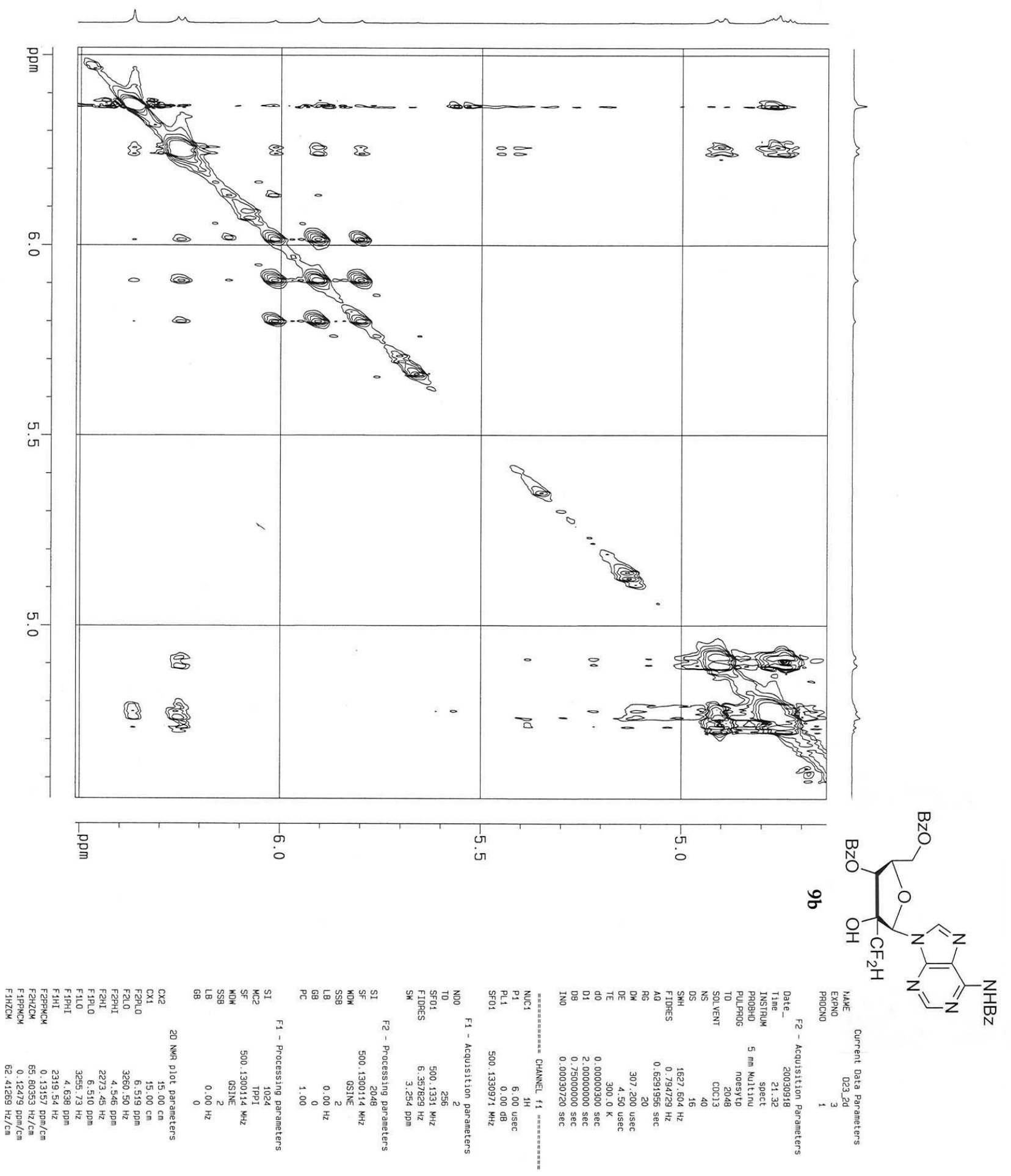




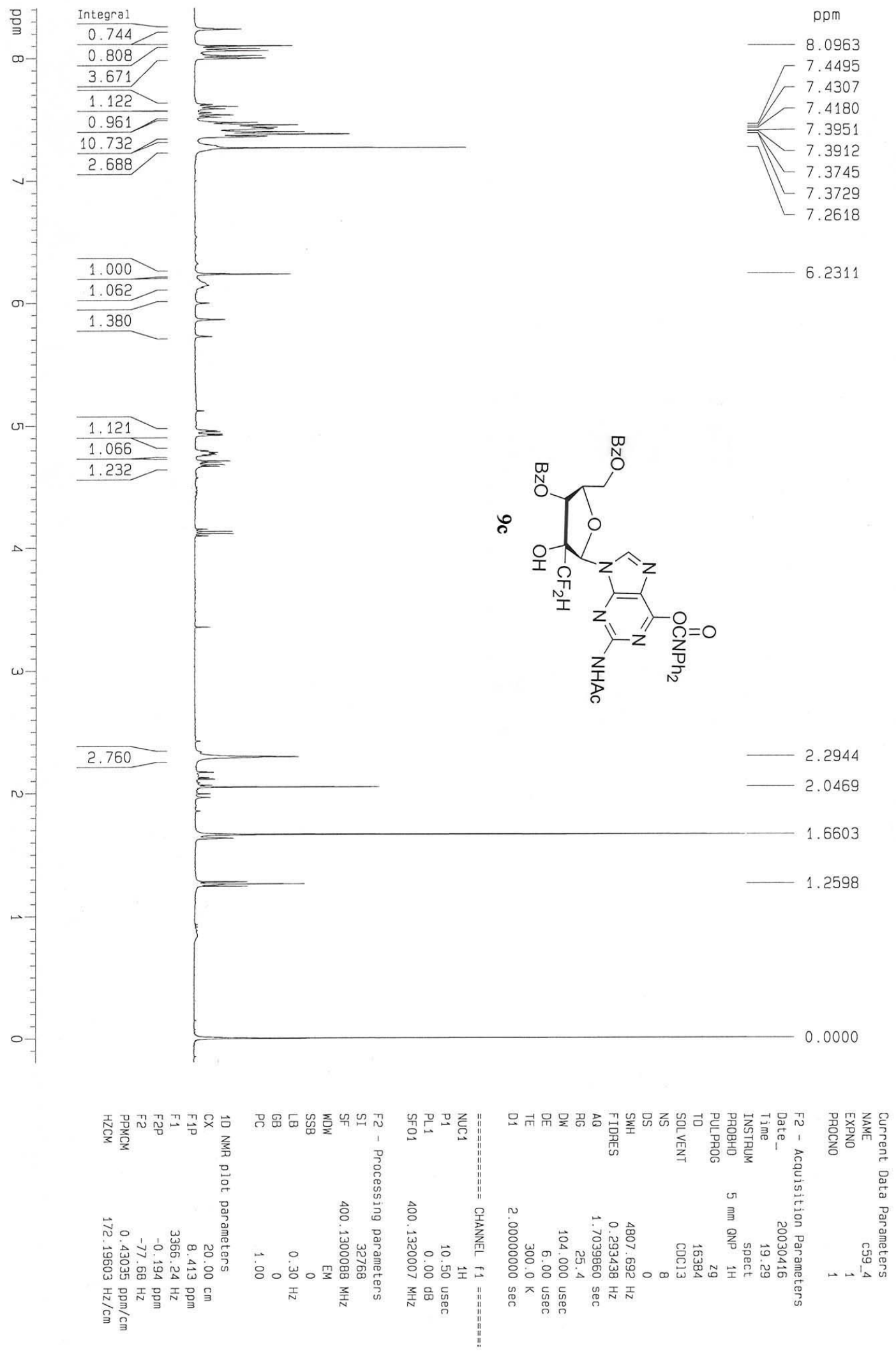



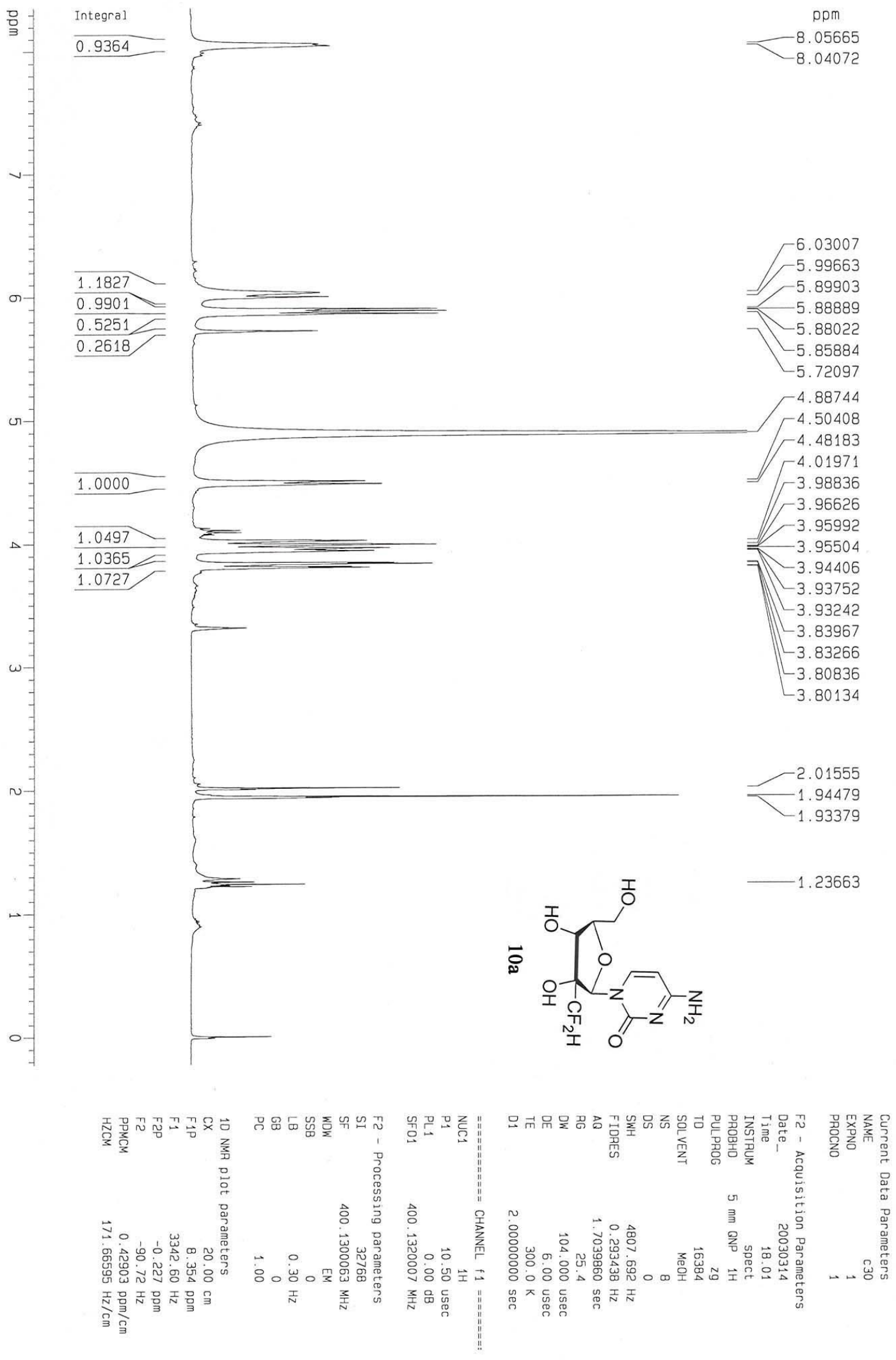

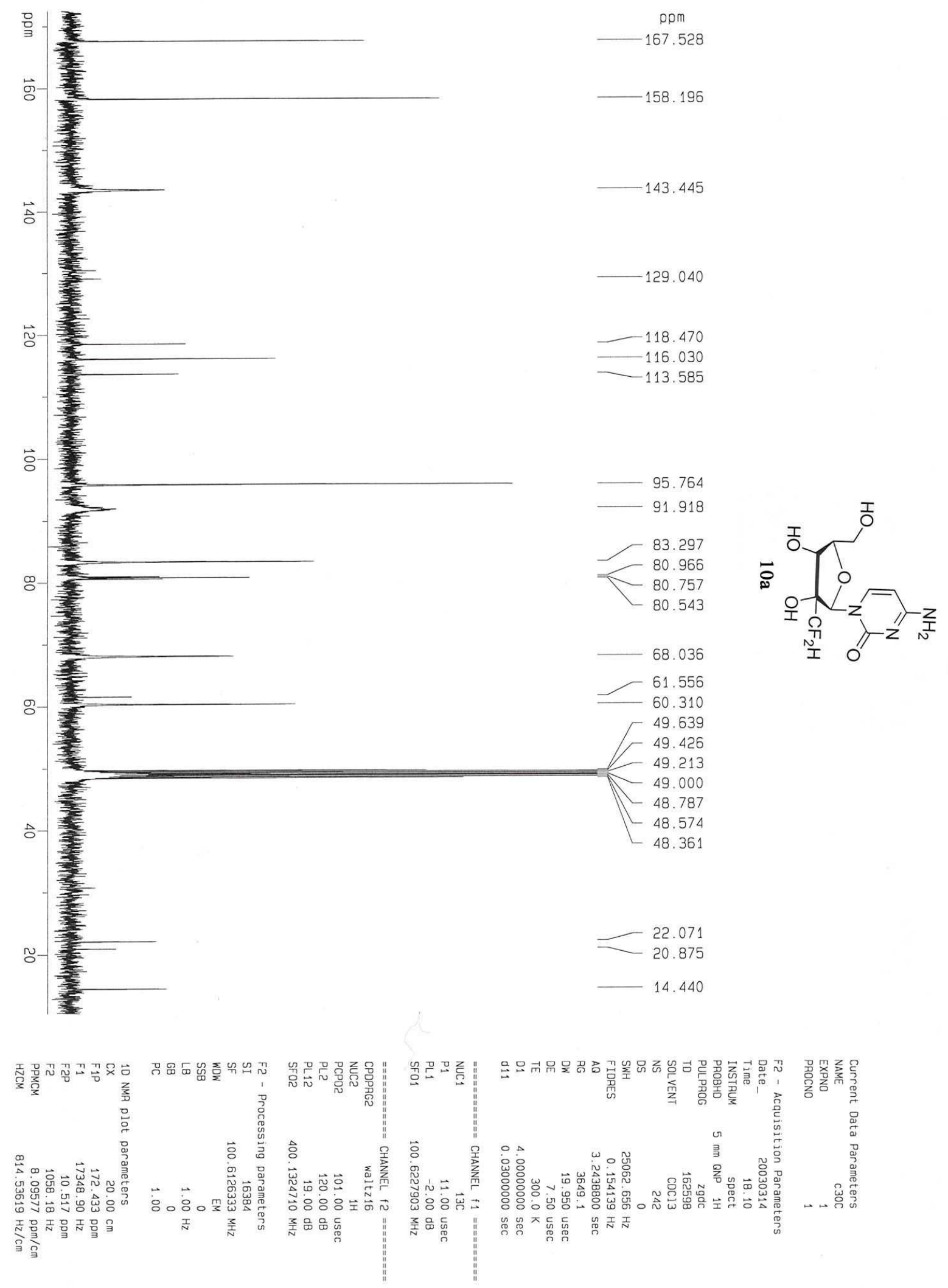

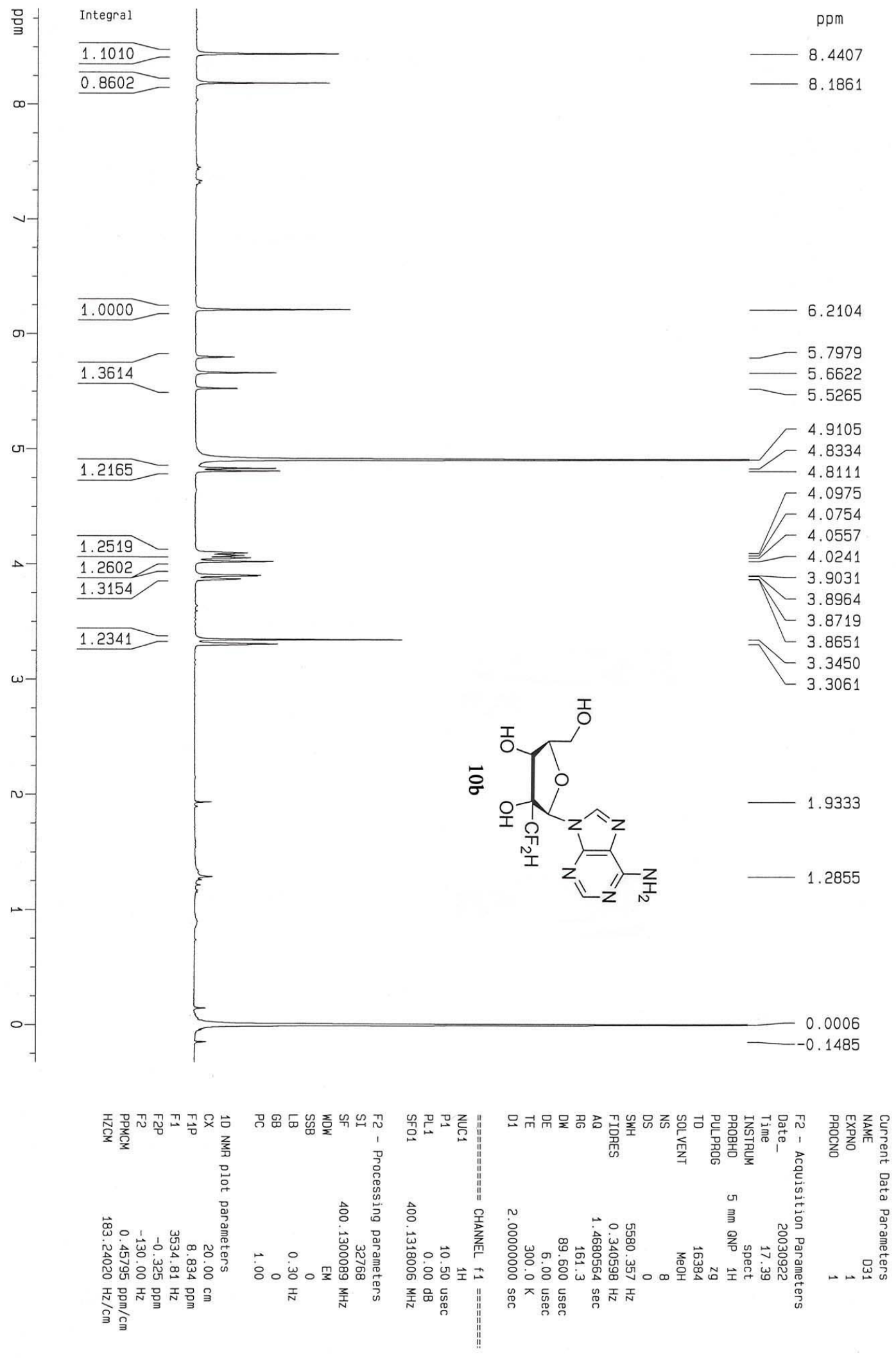

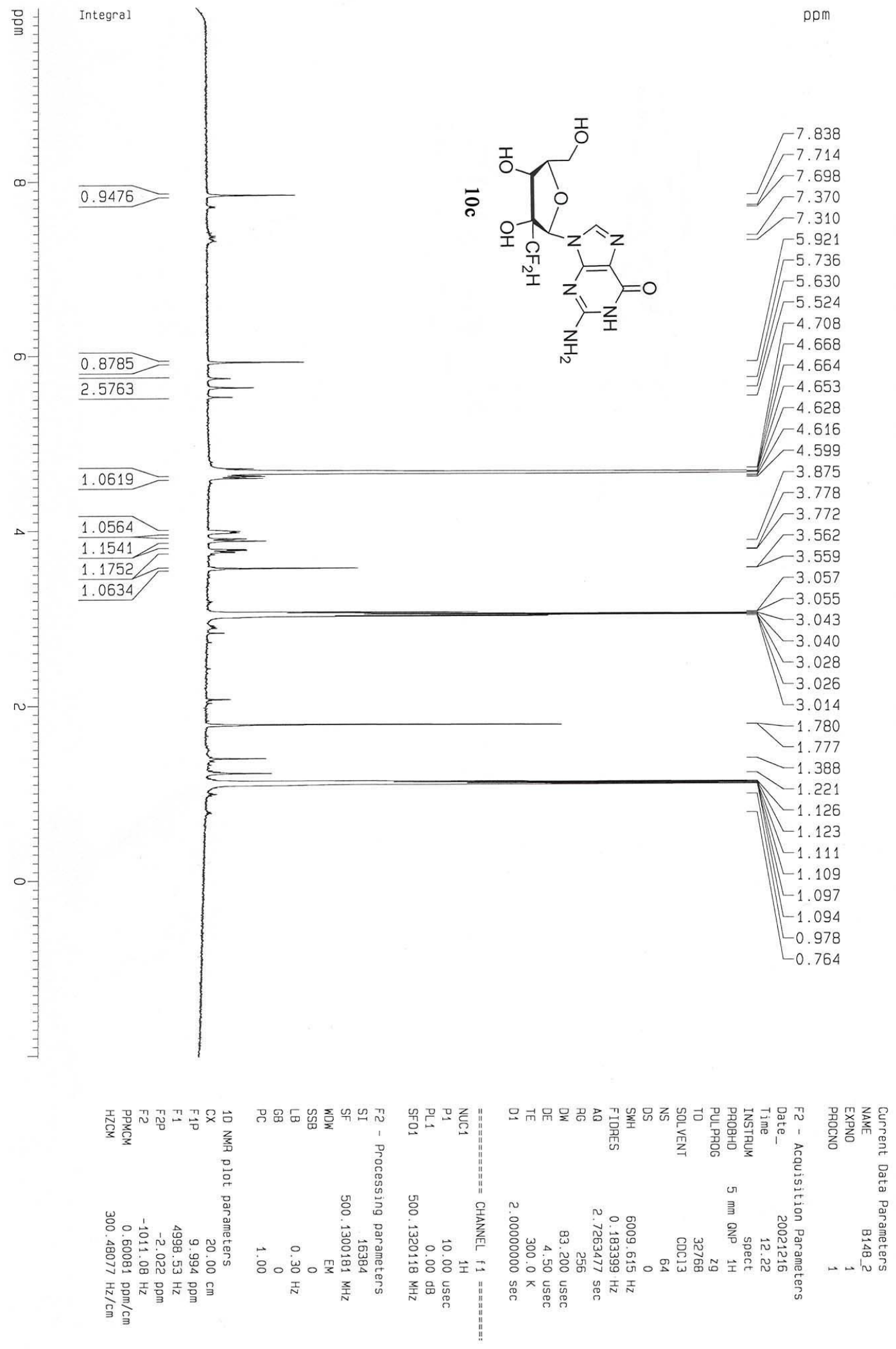

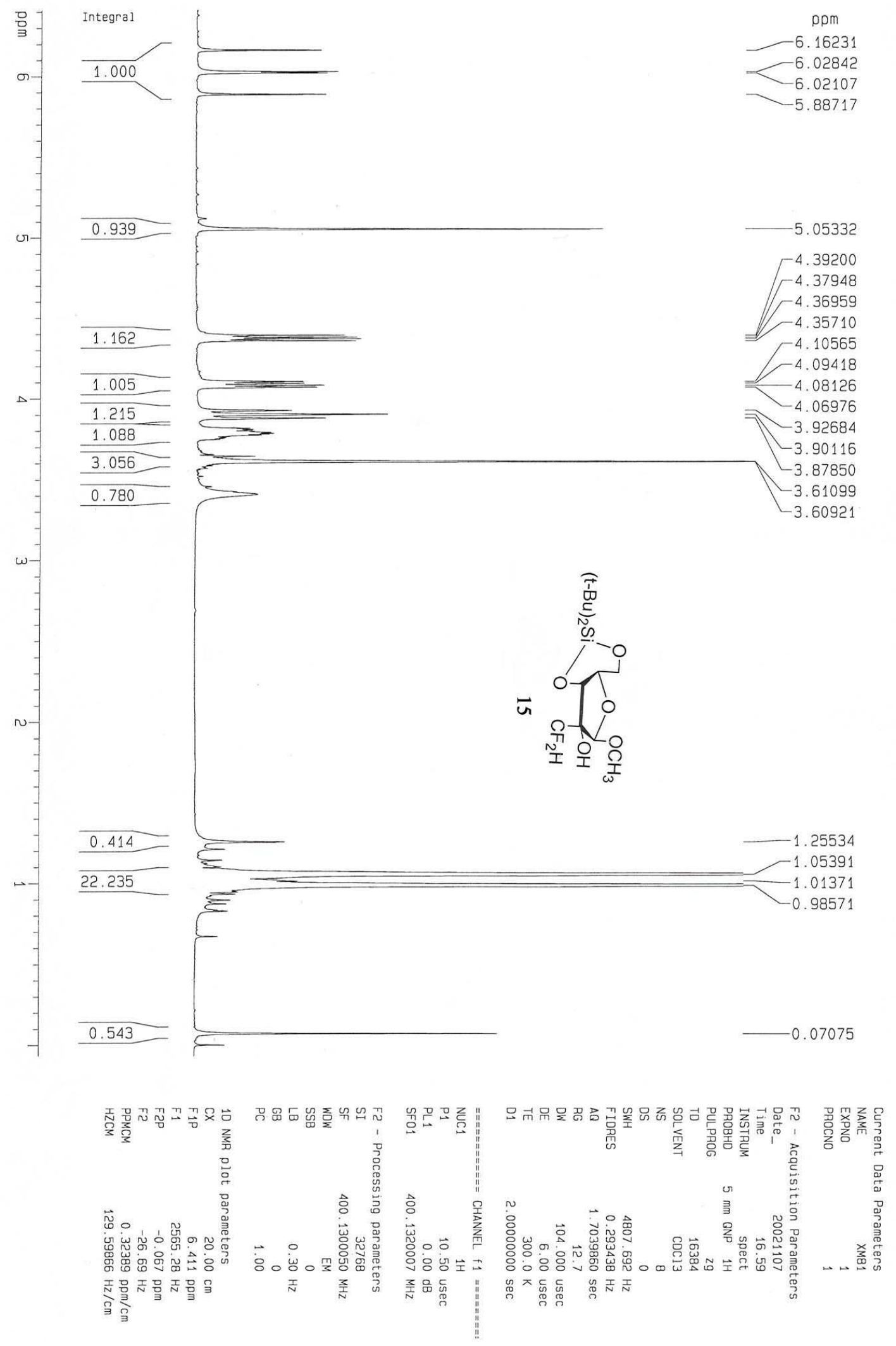


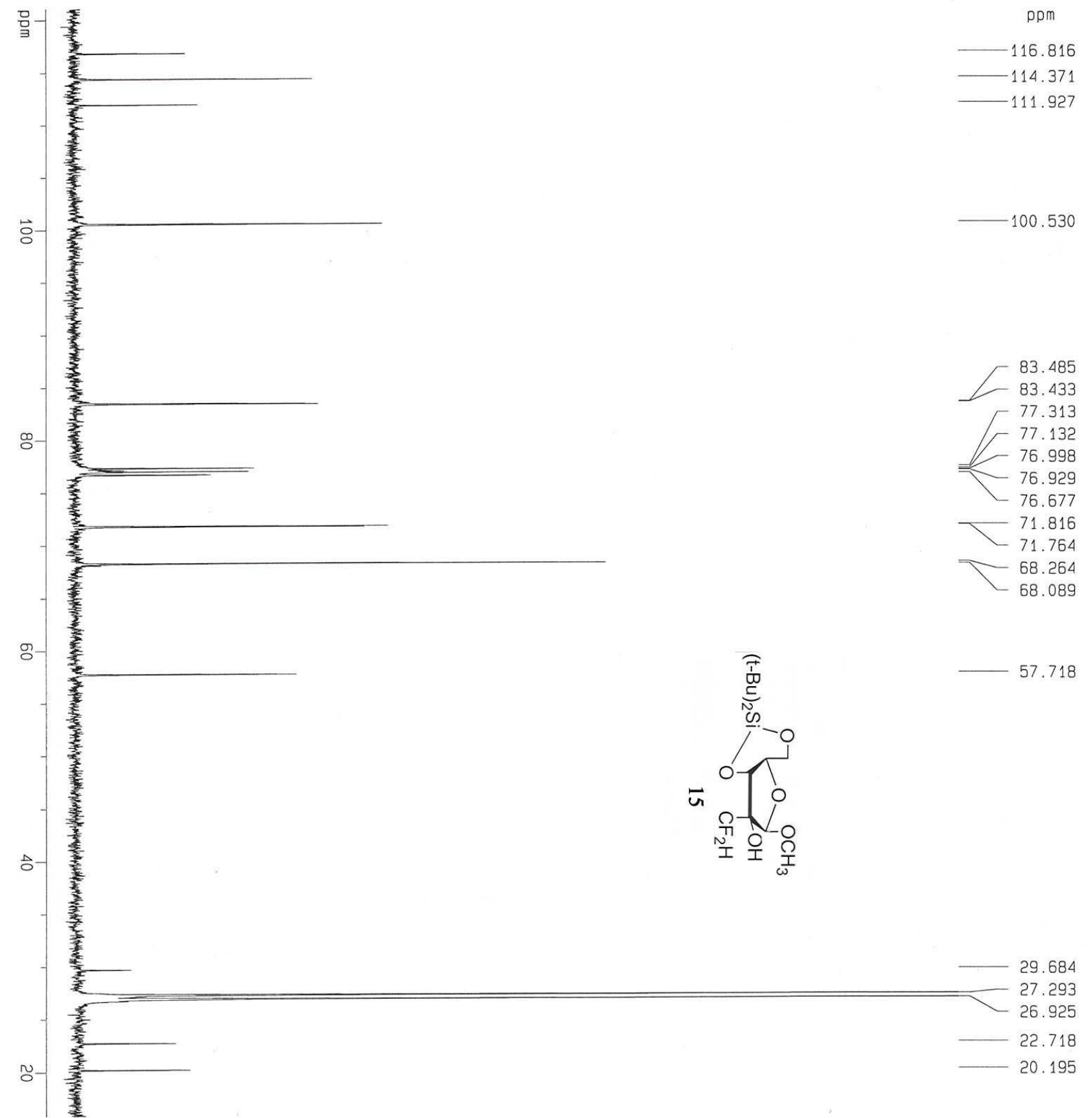

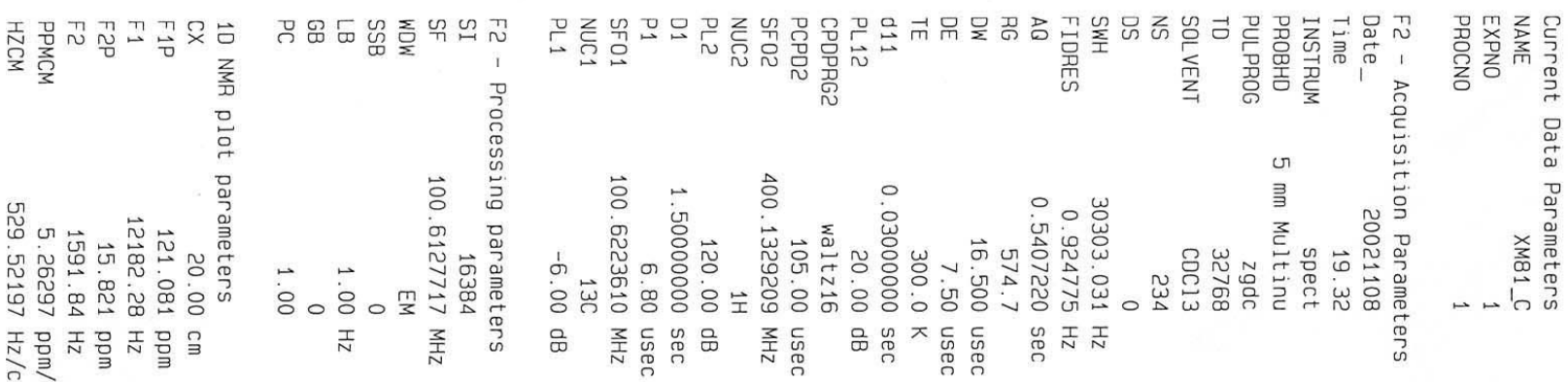


Integral
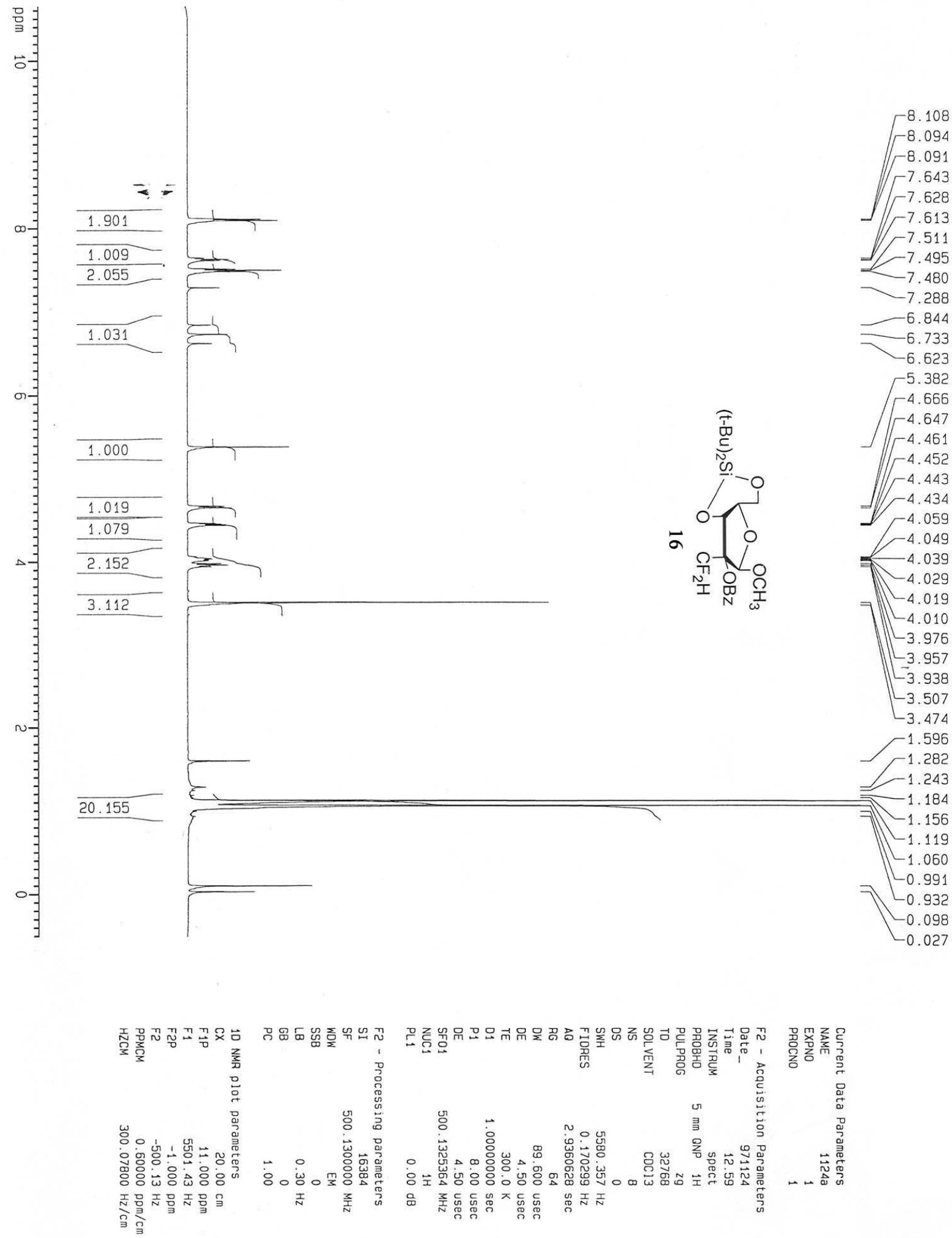

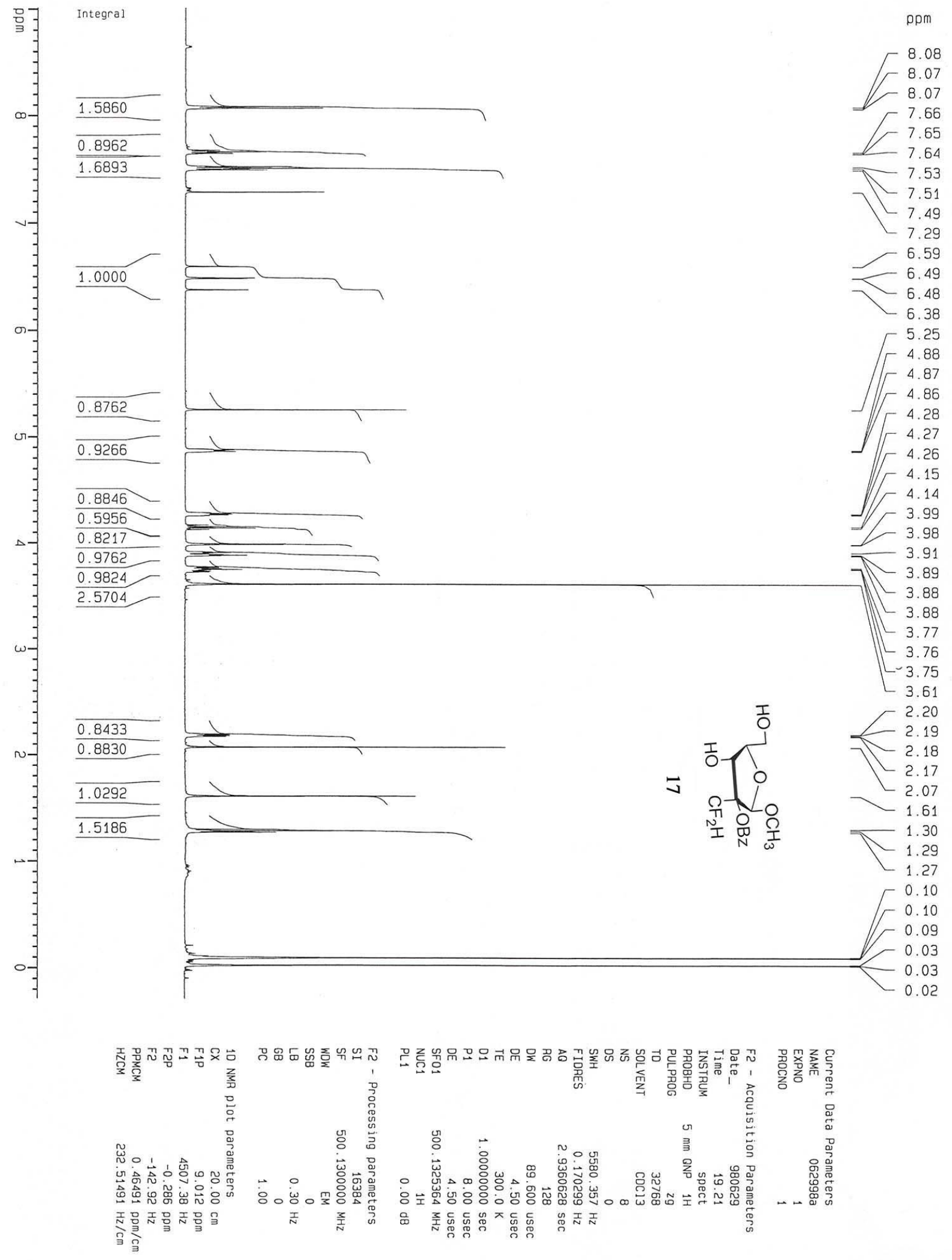


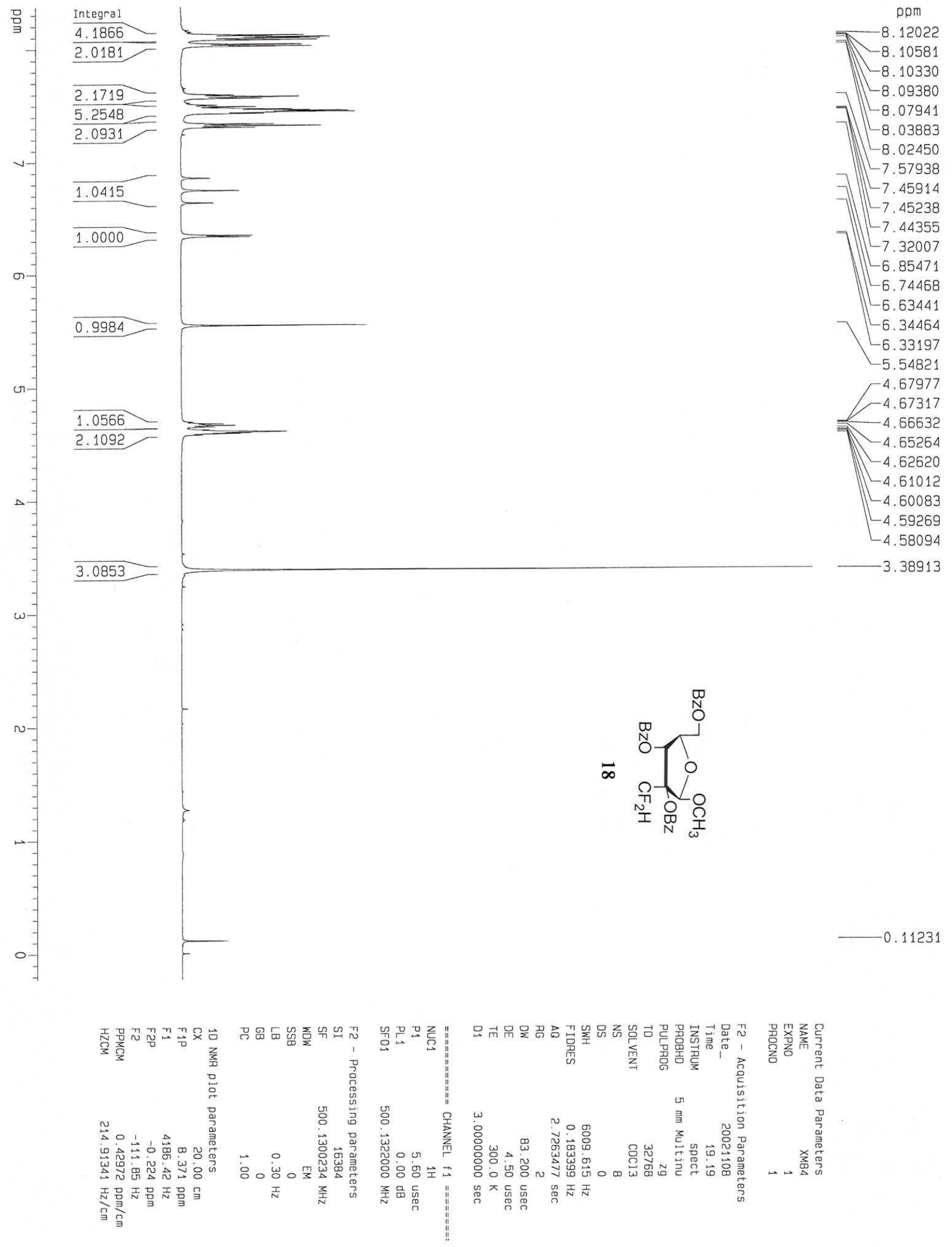




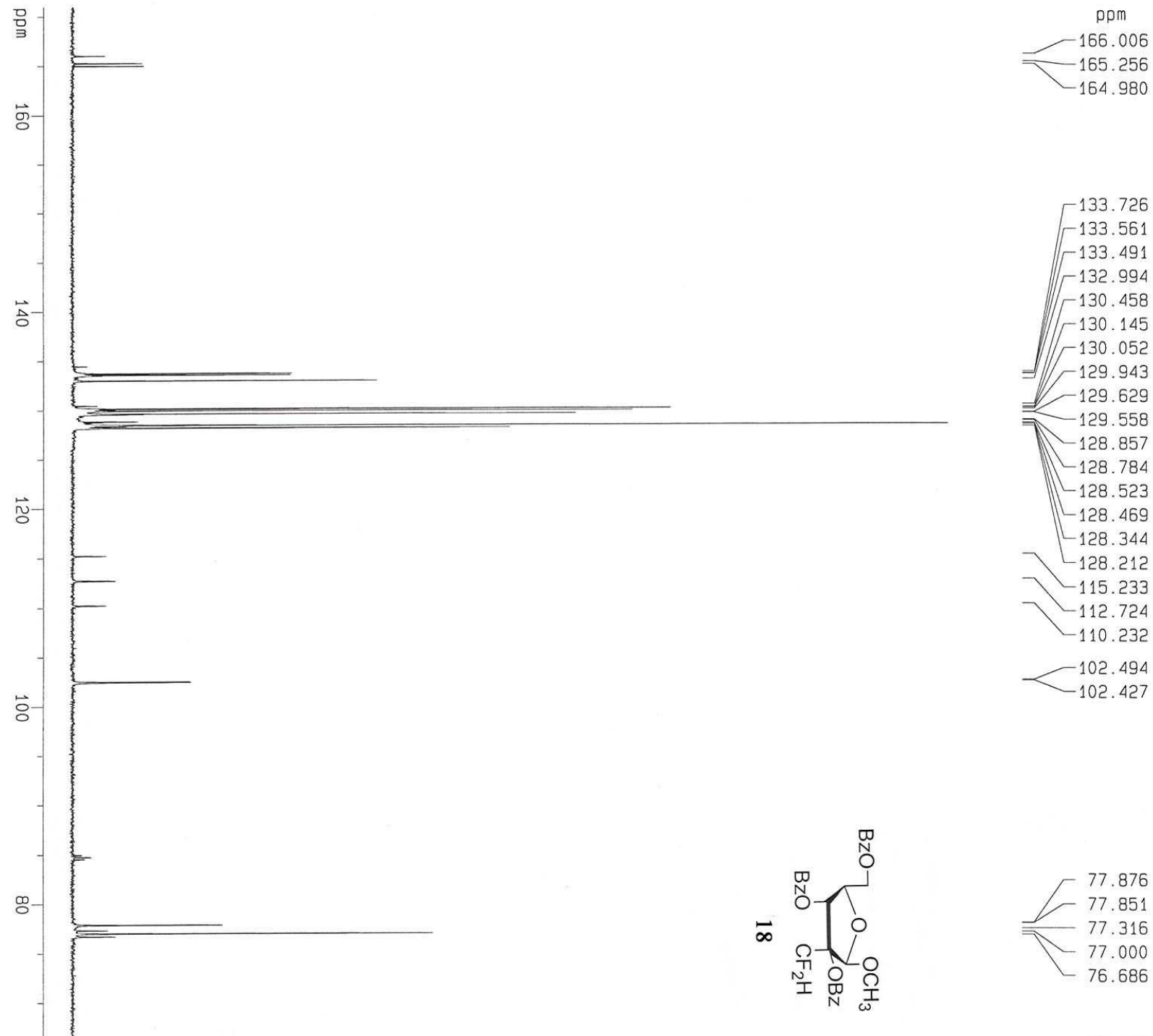

65.482

\section{8}

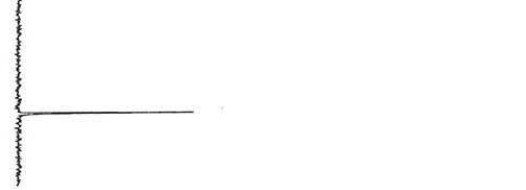

55.775

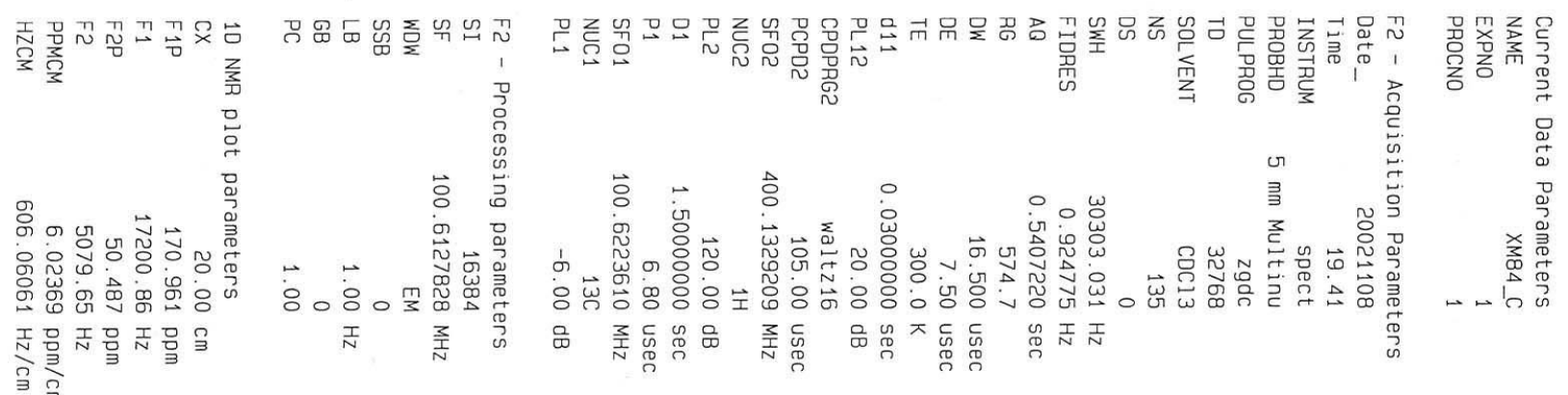




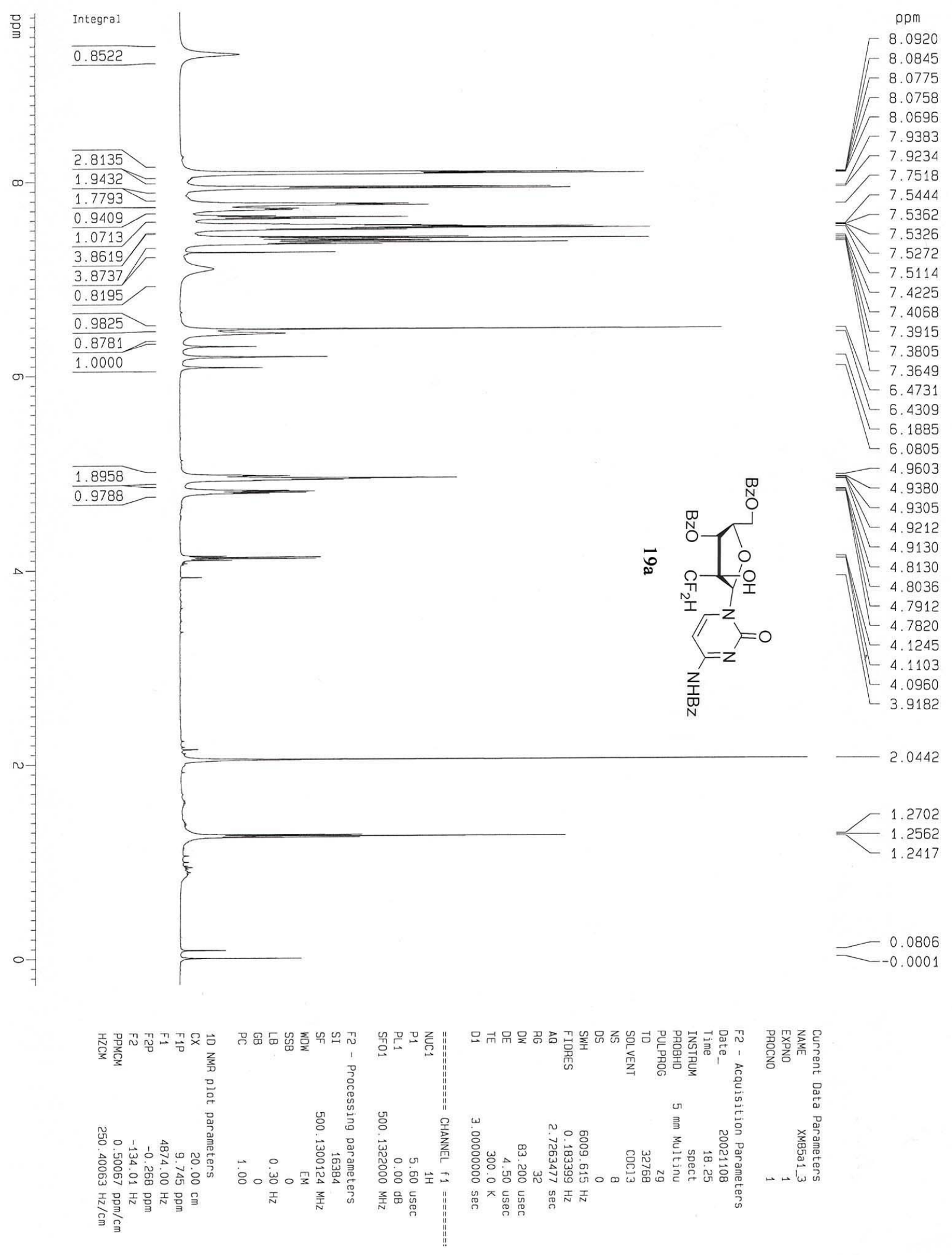




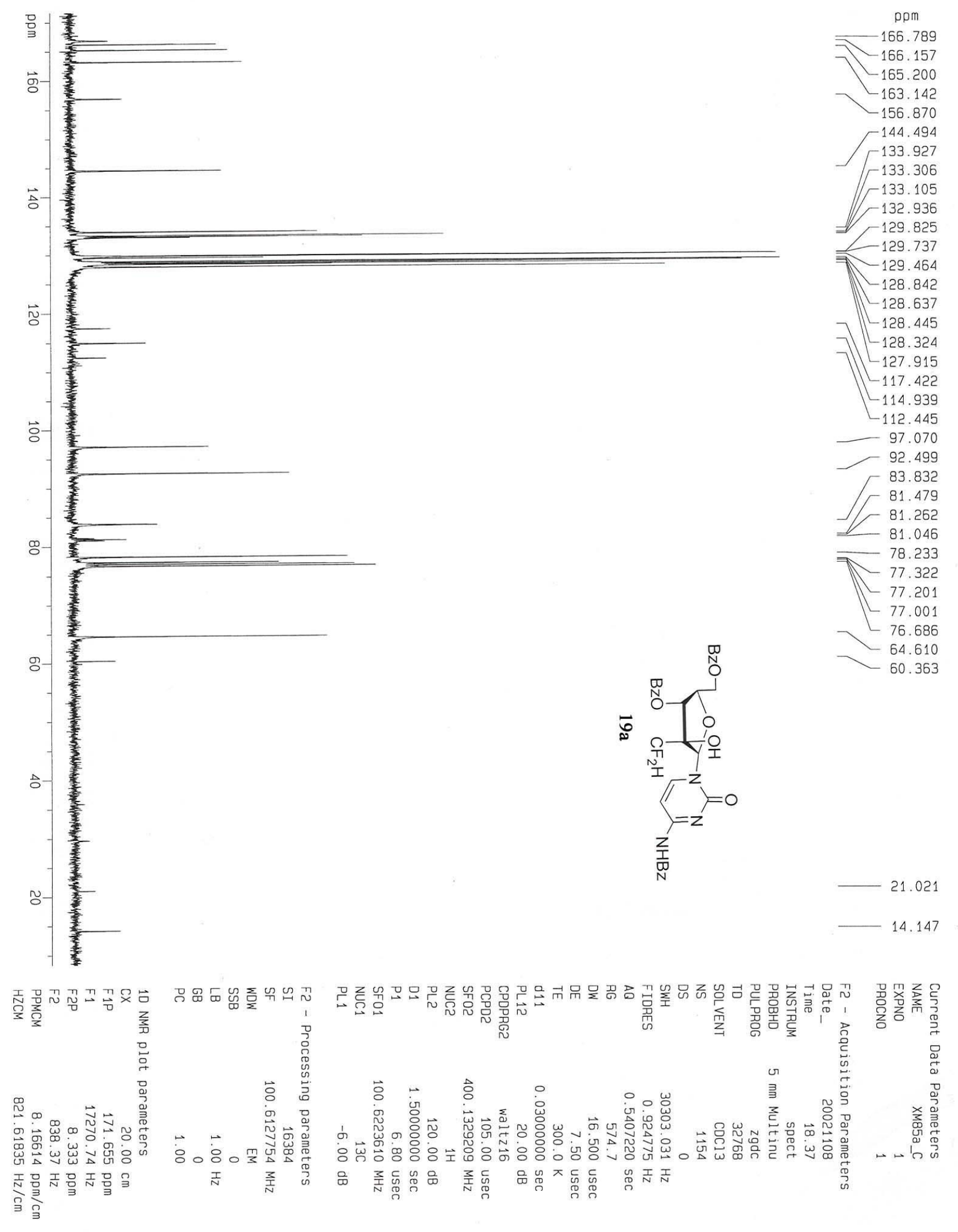




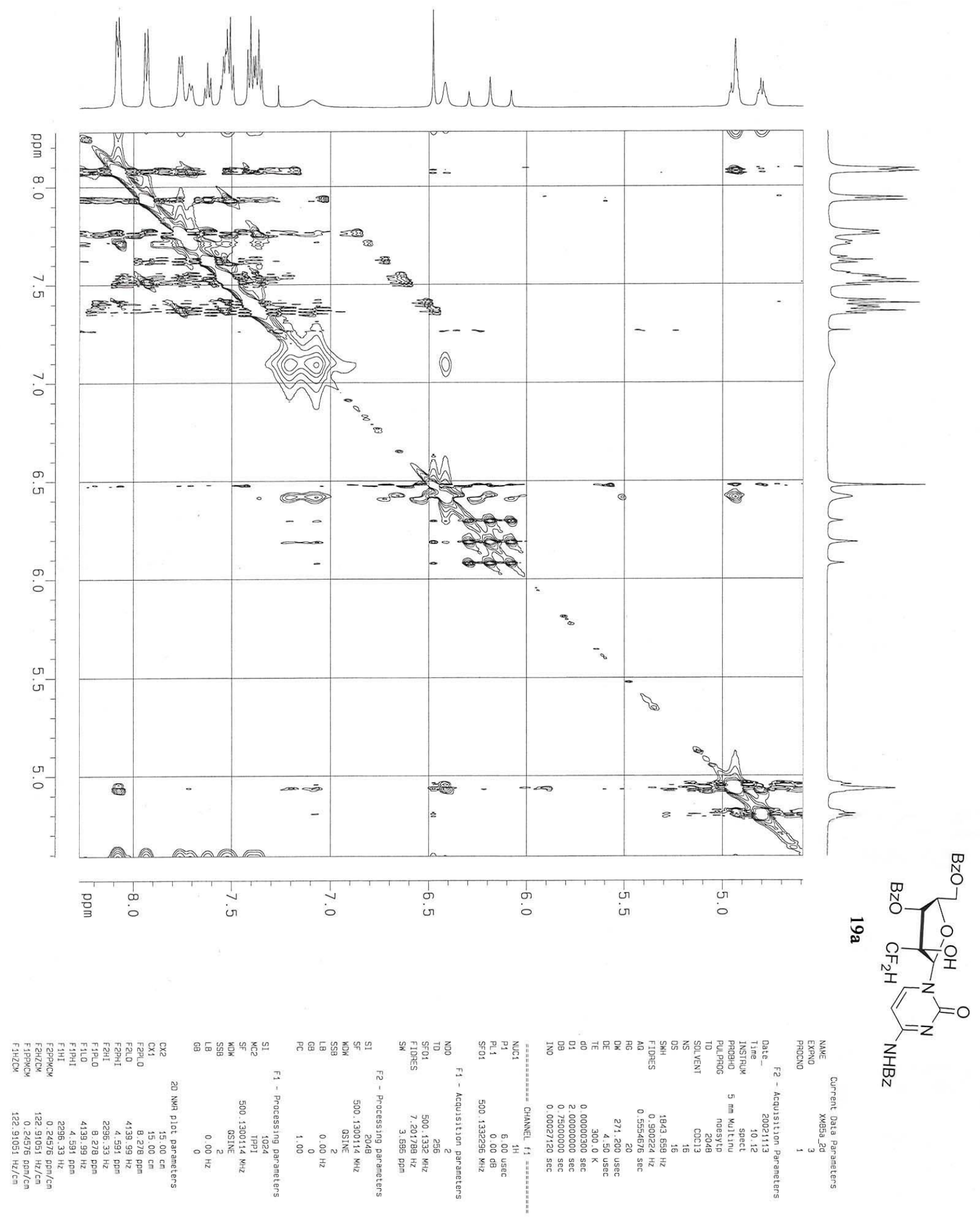



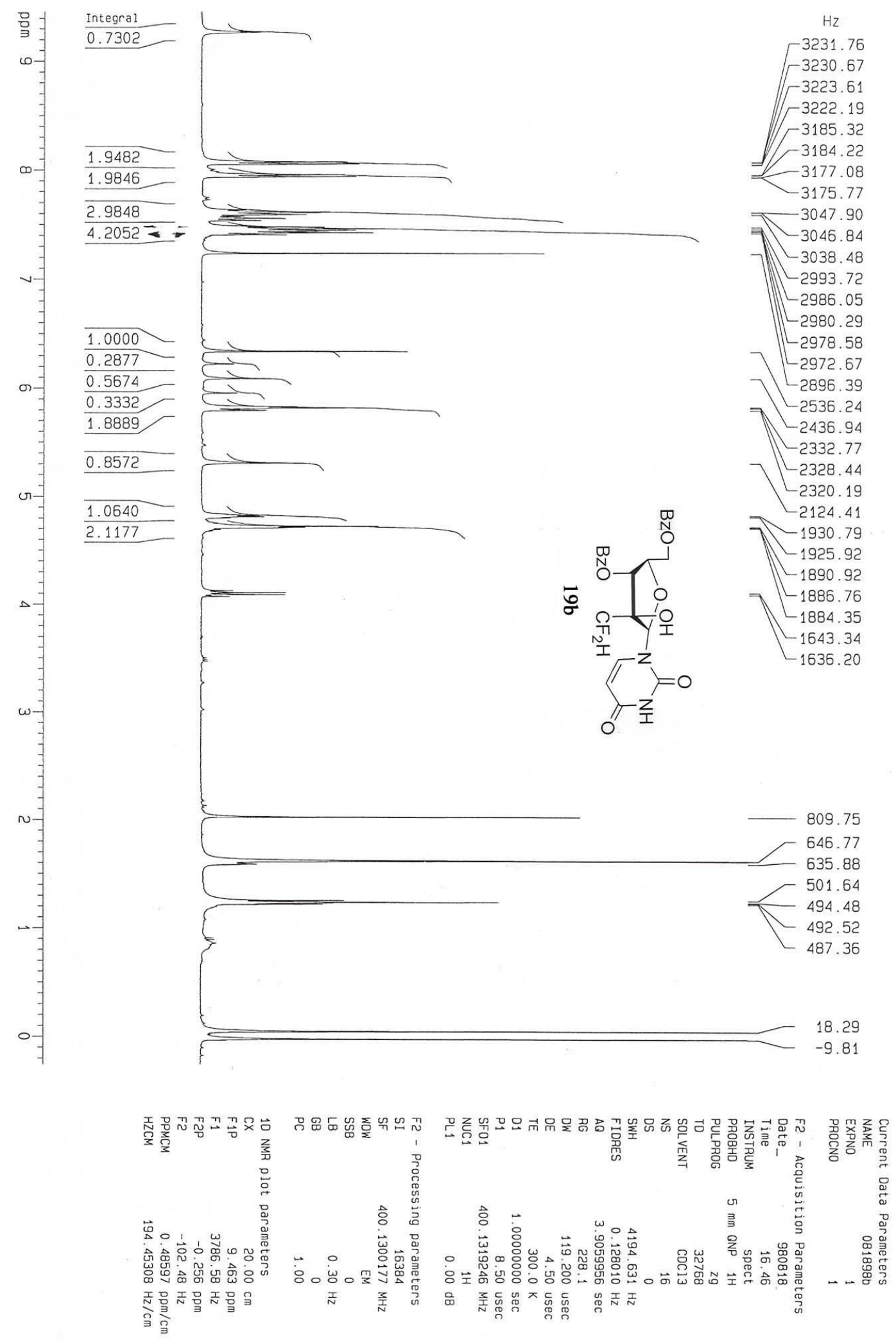

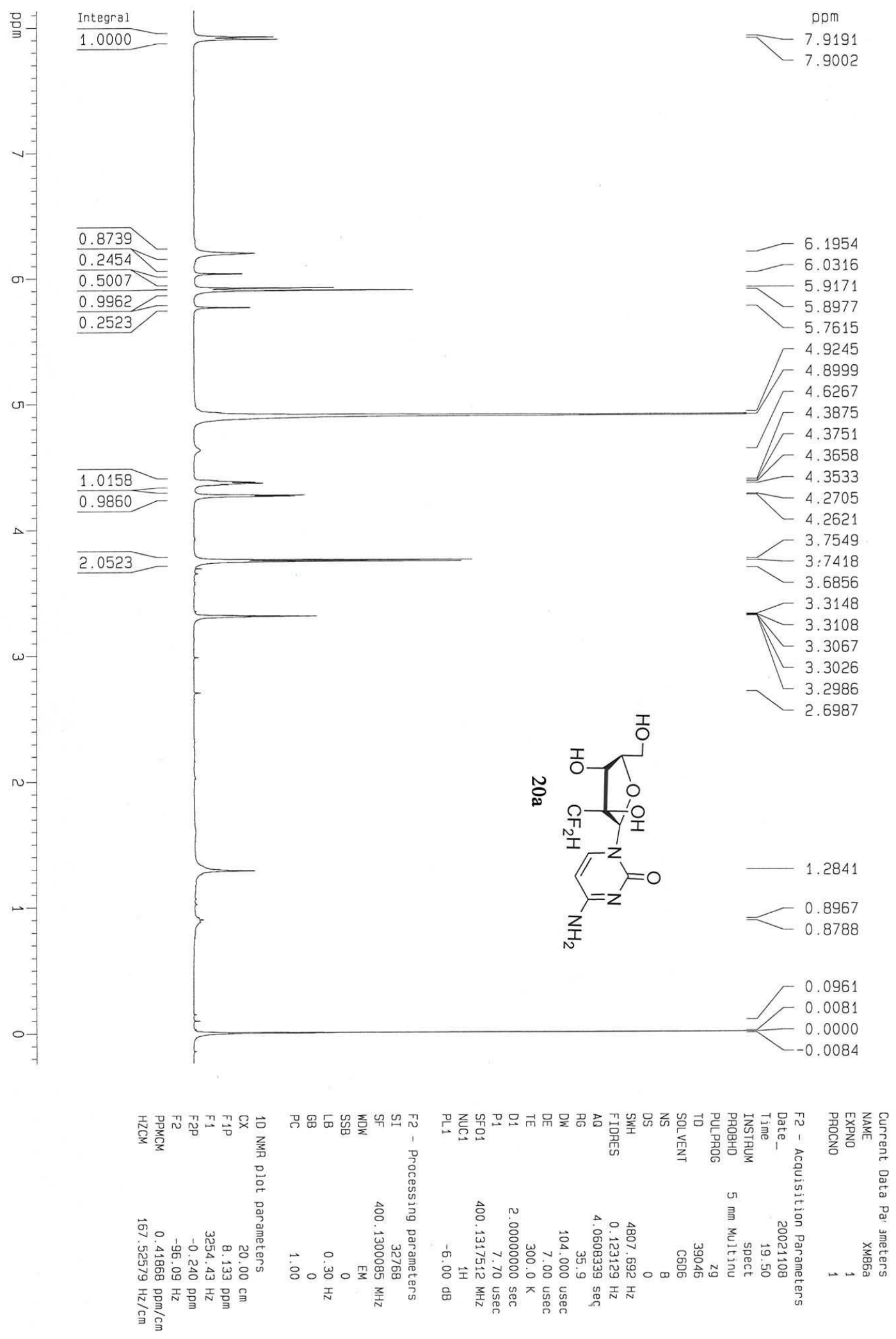


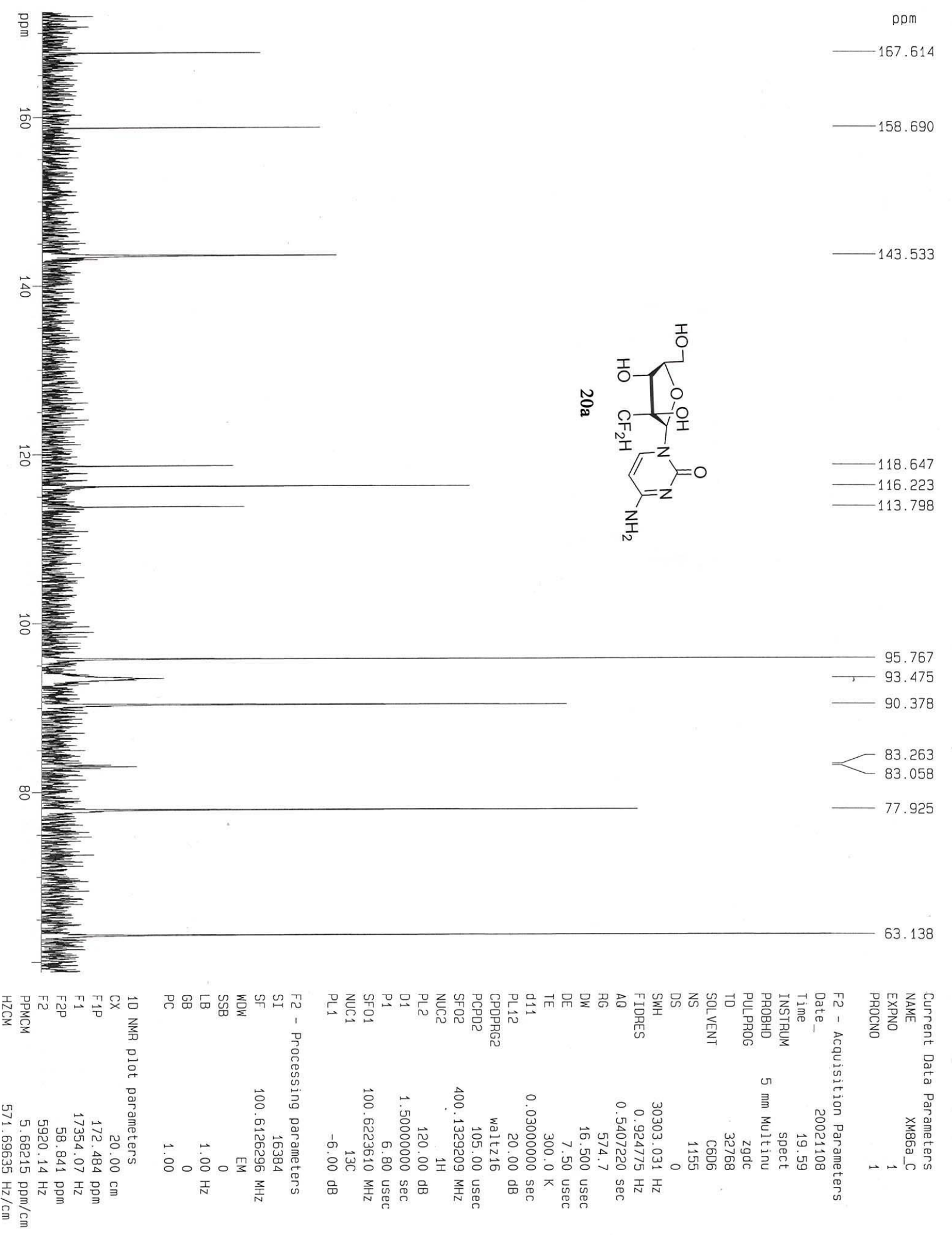



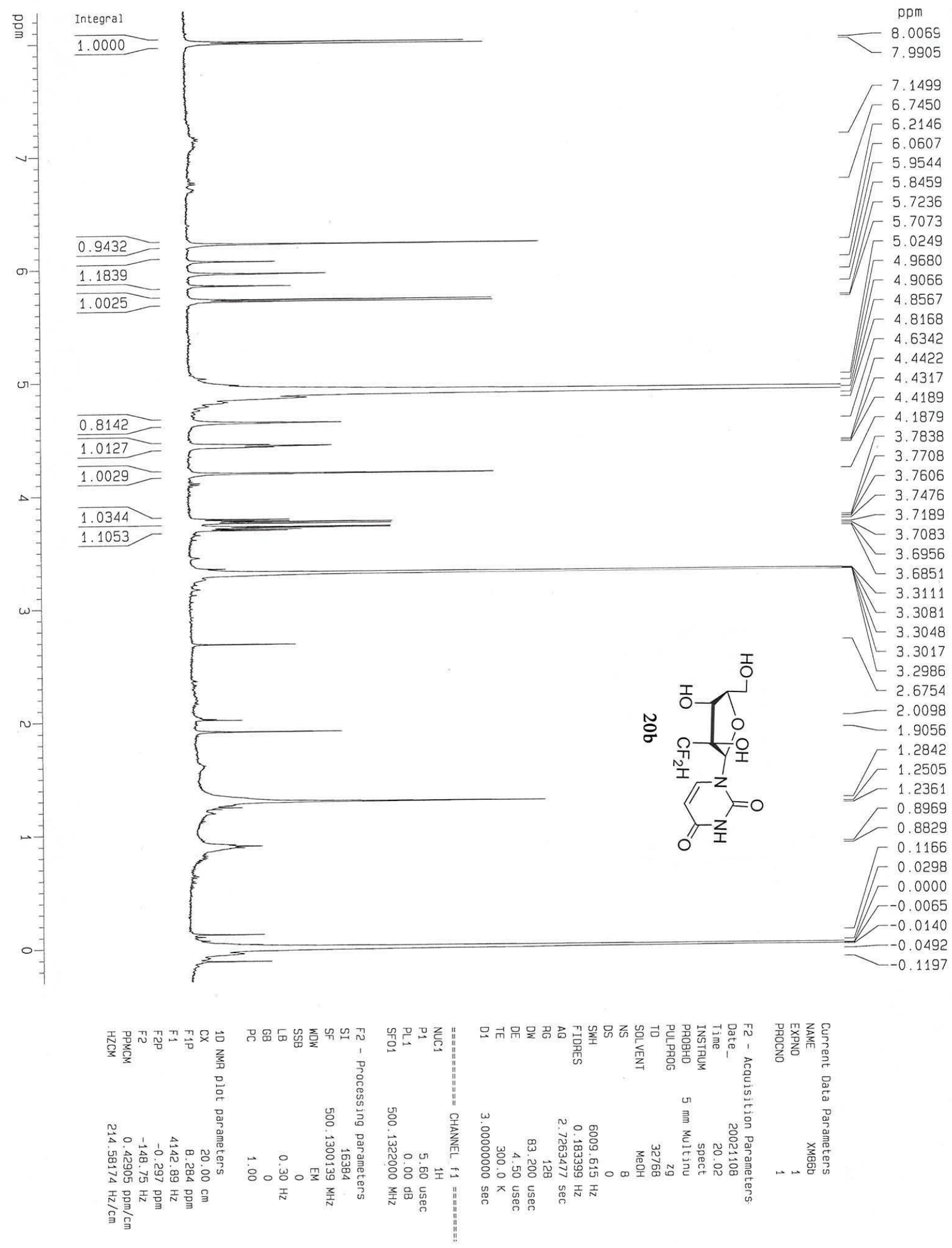


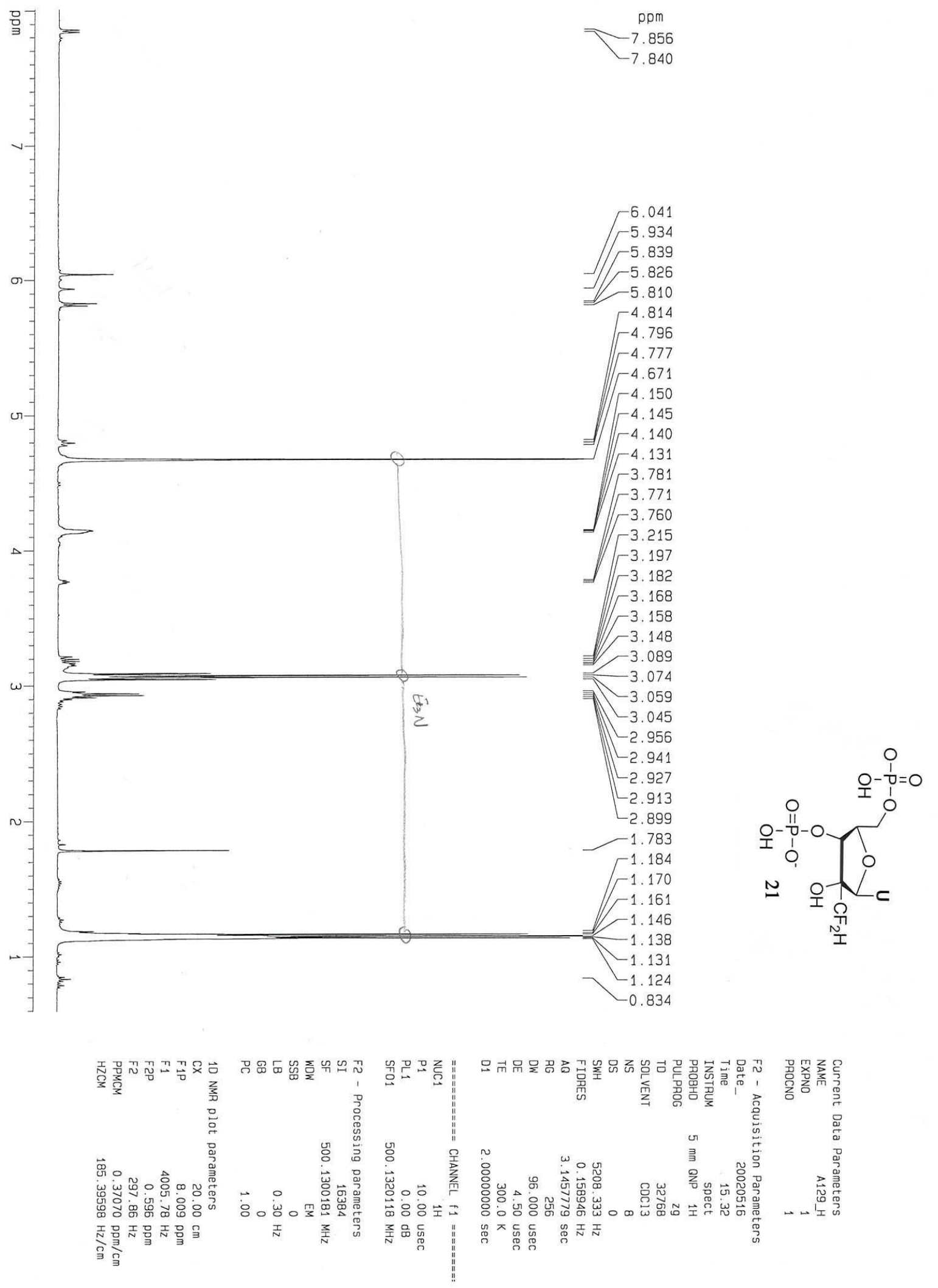




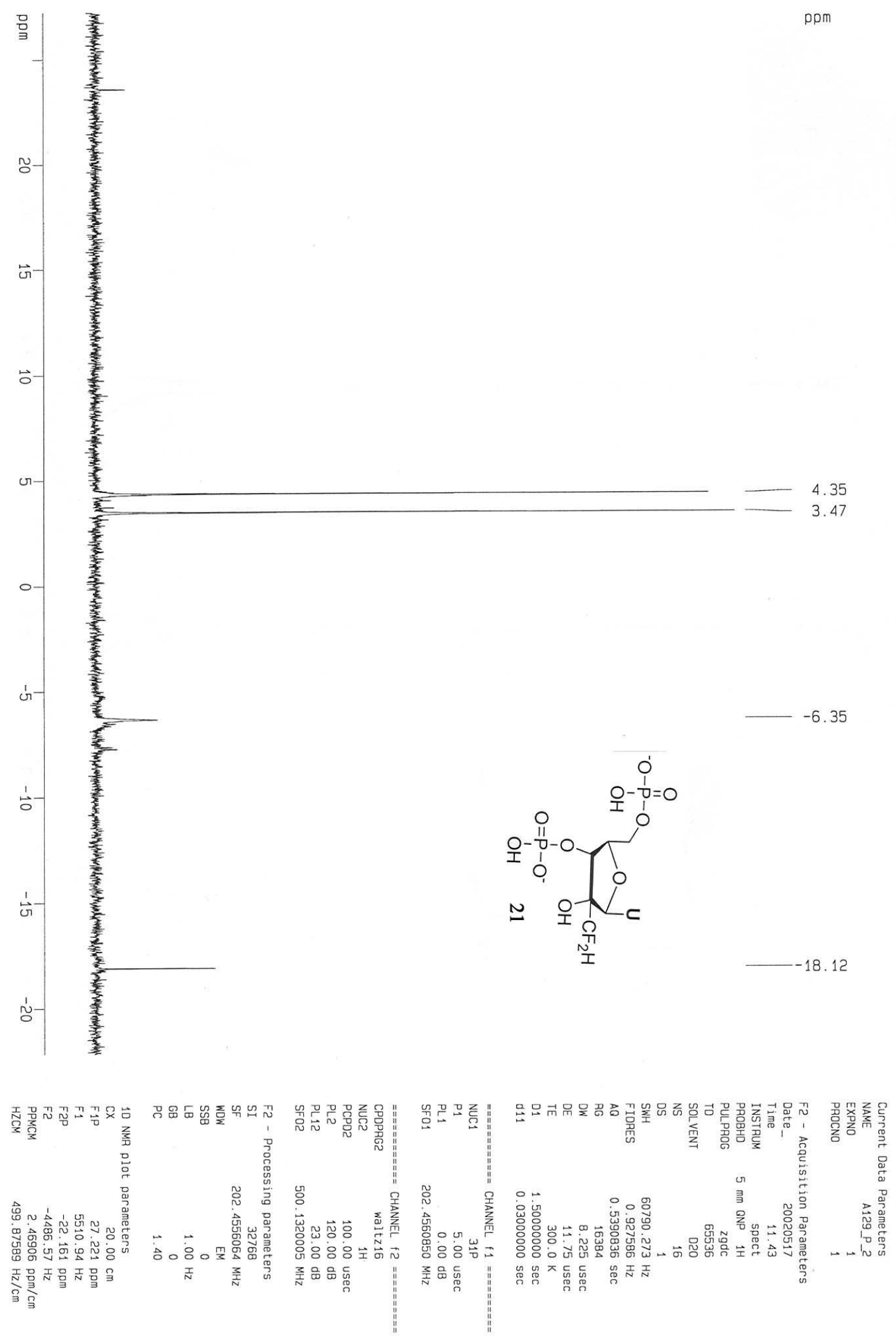




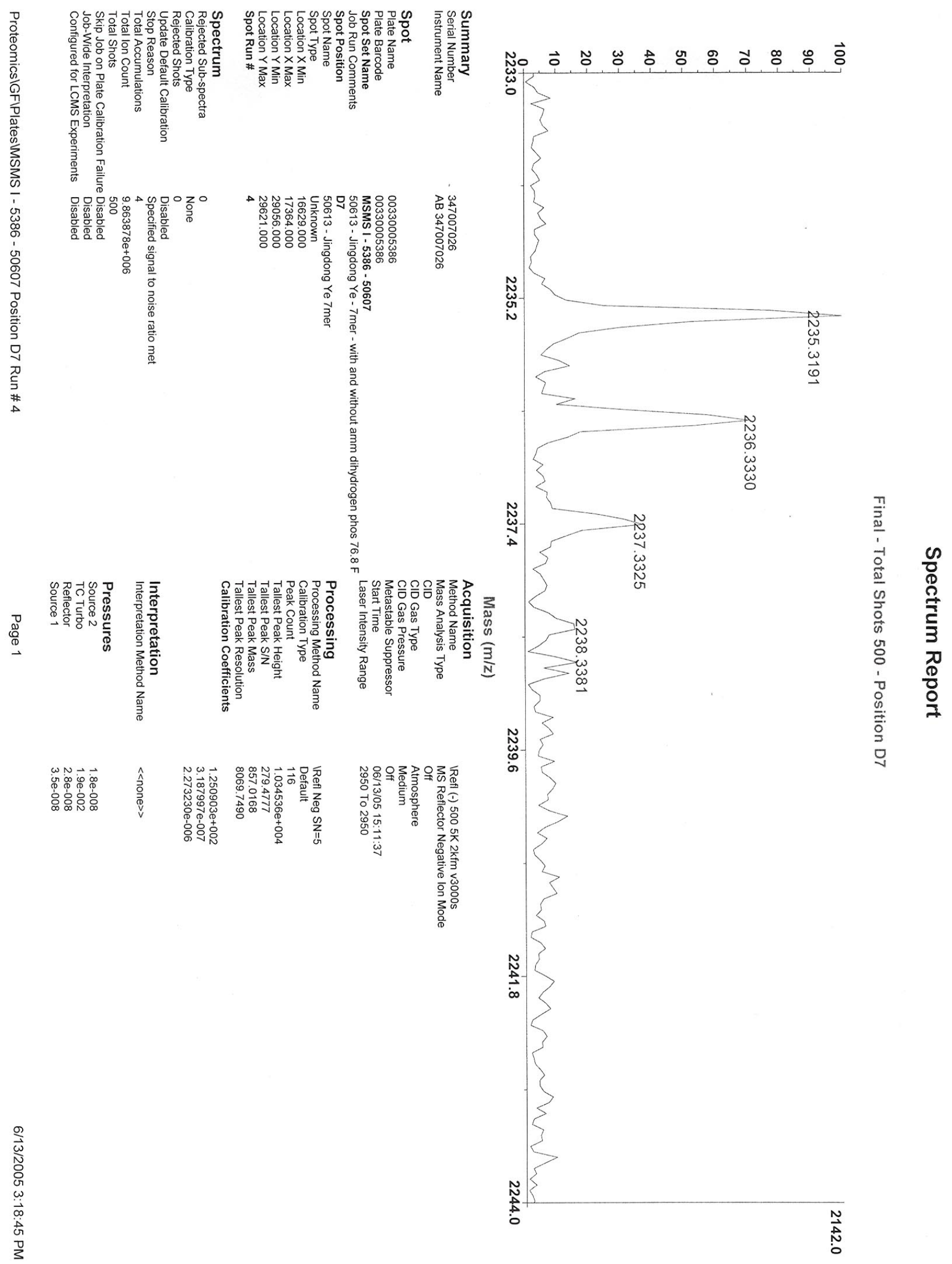


P1 nuclease digestion. ${ }^{*} \mathrm{p}(\mathrm{dN})_{12} \mathrm{rU}_{2^{\prime} \mathrm{CF} 2 \mathrm{H}}(\mathrm{dN})_{12}\left(\right.$ or $\left.{ }^{*} \mathrm{p}(\mathrm{dN})_{12} \mathrm{rU}(\mathrm{dN})_{12}\right)$ was incubated in $\mathrm{P} 1$ nuclease buffer in the presence of $0.01 \mathrm{mg} / \mathrm{ml} \mathrm{P} 1$ nuclease (USB) for $10 \mathrm{~min}$ at $37{ }^{\circ} \mathrm{C}$. The mixture was then heated at $90{ }^{\circ} \mathrm{C}$ for 1 minute, combined with gel loading buffer (final concentration: $50 \mathrm{mM}$ Tris$\mathrm{HCl}, \mathrm{pH} 8,3.5 \mathrm{M}$ urea and $0.0025 \%$ (w/v) each of bromophenol blue and xylene cyanol) and separated by $20 \%$ sequencing PAGE. Figure S1 shows the digestion pattern. The shorter P1 digestion products of the $\mathrm{CF}_{2}$ oligonucleotide, arising from cleavage upstream of the modification (12 nucleotides and less), comigrate with their wild-type counterparts during PAGE. This is expected, as these products lack the modification and therefore are identical to those produced from wild-type oligonuleotide. The 12 mer was assigned using the oligonucleotide from which the modified $\mathrm{CF}_{2}$ oligonucleotide was generated (Figure S1, lane 5). We observe no product corresponding to P1 cleavage at the site bearing the difluoromethyl group (13mer), suggesting that the modification hinders P1 activity. The longer P1 digestion products of the $\mathrm{CF}_{2}$ oligonucleotide, arising from cleavage downstream of the modification (14 nucleotides and greater), migrate modestly slower than their wild-type counterparts, presumably due to the presence of the difluoromethyl modification. The species labeled as A and B in lanes 3 and 4 respectively, are present in the undigested controls (lanes 1 and 2, respectively) and most likely correspond to cleavage products arising from internal transphosphorylation at the ribose linkage. 


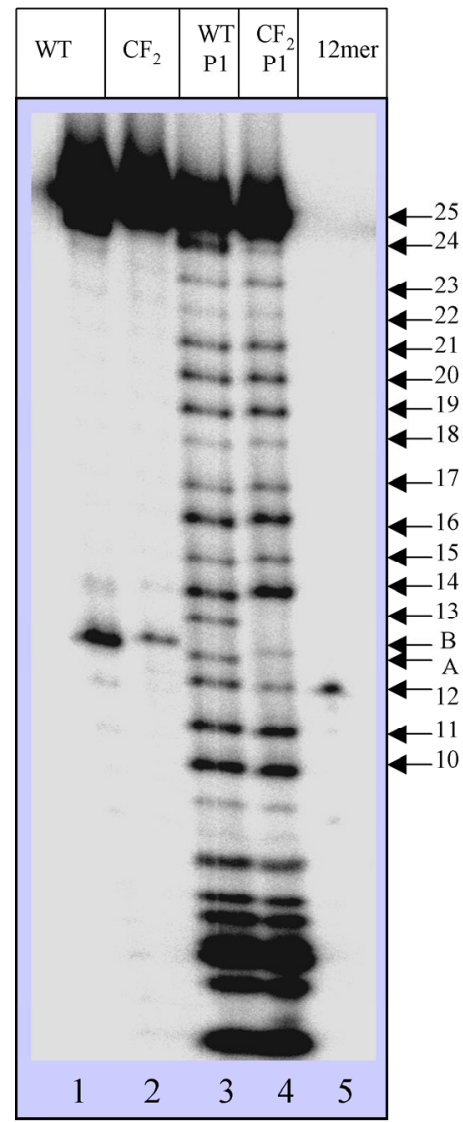

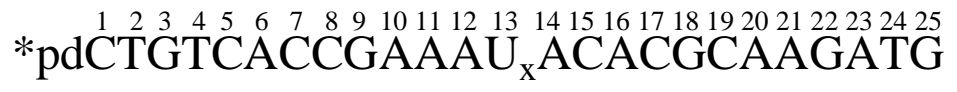

$$
\mathrm{U}_{\mathrm{x}}=\mathrm{U} \text { or } \mathrm{U}_{2} \mathrm{CF}_{2} \mathrm{H}
$$

Figure S1. Nuclease P1 digestion of chimeric oligonucleotides containing uridine or 2'-C- $\beta$ difluoromethyluridine. Lane 1, WT, *pd(CTGTCACCGAAA)rUd(ACACGCAAGATG), input; Lane 2, $\mathrm{CF}_{2}$, ${ }^{*}$ pd(CTGTCACCGAAA) $\mathrm{rU}_{2} \mathrm{CF}_{2} \mathrm{H}$ (ACACGCAAGATG), input; Lane 3, WT, with P1 nuclease; Lane 4, $\mathrm{CF}_{2}$, with P1 nuclease; Lane 5, 12mer, *pd(CTGTCACCGAAA). 